
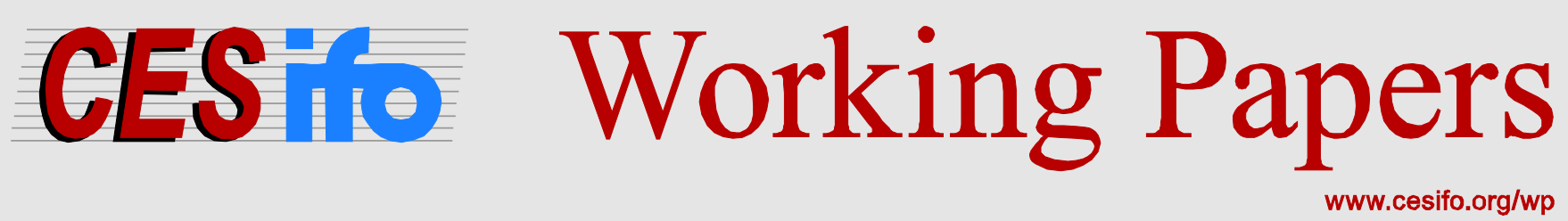

\title{
Management Incentives under Formula Apportionment \\ - Tax-Induced Distortions of Effort and Compensation in a Principal-Agent Setting -
}

\author{
Jan Thomas Martini \\ Rainer Niemann \\ Dirk Simons
}

CESIFO WORKING PAPER NO. 4908

CATEgORY 1: Public FinANCE

JULY 2014

An electronic version of the paper may be downloaded

- from the SSRN website:

- from the RePEc website:

www.SSRN.com

www.RePEc.org

- from the CESifo website:

www.CESifo-group.org/wp

\section{CESifo}




\title{
Management Incentives under Formula Apportionment - Tax-Induced Distortions of Effort and Compensation in a Principal-Agent Setting -
}

\begin{abstract}
The introduction of a common consolidated corporate tax base (CCCTB) and tax allocation via formula apportionment (FA) is hotly debated in the European Union (EU) since more than a decade. While the literature has thoroughly analyzed the economic effects of FA from a macro-level perspective, the firm view has been added only recently. Within this micro-level framework discussing possible tax-induced distortions of multi-jurisdictional entities' (MJE) decisions becomes feasible. Anticipating the reactions of MJEs to the introduction of FA requires considering delegation and incentivisation, because management decisions are influenced by principal agent relationships. How FA affects the demand for managerial effort is a hitherto neglected research question. Accordingly, the objective of this paper is to highlight the tax-induced distortions of managerial incentives caused by FA. For this purpose we set up a LEN-type principal-agent model with agents in two different jurisdictions. Compared to the case with separate taxation (ST) the principal demands increased effort and pays an increased compensation to managers in low-tax jurisdictions, if payroll enters the FA formula. Managers in high-tax jurisdictions face the opposite effect. Further, the composition of the compensation packages changes. Overall, net profit increases, because FA offers potential for profit shifting.
\end{abstract}

JEL-Code: H250, M410.

Keywords: common consolidated corporate tax base, formula apportionment, managerial compensation, multi-jurisdictional entities, principal-agent-problem.

Jan Thomas Martini

University of Bielefeld / Germany

tmartini@wiwi.uni-bielefeld.de
Rainer Niemann

University of Graz / Austria

niemann@uni-graz.at

Dirk Simons

University of Mannheim / Germany

simons@bwl.uni-mannheim.de 


\section{Introduction}

Institutions of the European Union (EU) favor the introduction of a common consolidated corporate tax base (CCCTB) with formula apportionment (FA) as a tax revenue allocation mechanism. ${ }^{1}$ Despite its supposed benefits, like a reduction of tax compliance costs or the increased transparency in tax competition, ${ }^{2}$ FA could have unintended negative economic consequences. Especially, the set of factors included in the formula and the formula weights are crucial determinants of these effects. Among the factors included in the prominent Massachusetts formula - sales, payroll, and assets - sales receive the greatest attention in the literature ${ }^{3}$. While initially most U.S.-states applied FA with equal weights, several states implemented a double-weighted sales formula, others even introduced a sales-only formula. ${ }^{4}$ This development emphasizes tax legislators' reservations against payroll as an apportionment factor. ${ }^{5}$ Despite this development in the U.S. the European Commission issued a proposal on СССТВ including a labor-related factor composed of payroll and number of employees. ${ }^{6}$ Accordingly, this formula raises fears among EU-member states of detrimental effects on employment. For instance, a report prepared for the Irish Department of Finance estimates that countries like France

\footnotetext{
${ }^{1}$ See EU Commission (2011), EU Parliament (2012).

${ }^{2}$ The effects of FA on tax competition are analyzed, e.g., by Wellisch (2004) or Pethig/Wagener (2007).

${ }^{3}$ See e.g. Edmiston (2002), Eichner/Runkel (2008), and Garst (2008).

${ }^{4}$ See for instance Edmiston/Arze del Granado (2006), Lohman (2012), Institute on Taxation and Economic Policy (2012), or Federation of Tax Administrators (2013).

${ }^{5}$ See Goolsbee/Maydew (2000).

${ }^{6}$ See EU Commission (2011), Article 86.
} 
$(+0.5 \%)$, Spain $(+0.2 \%)$, and Belgium $(+0.15 \%)$ would benefit from the introduction of FA in terms of employment, whereas countries like Ireland $(-1.3 \%)$, Luxembourg $(-1.15 \%)$, and Poland $(-1.0 \%)$ would face a decline in jobs. ${ }^{7}$ However, these studies consider FA from a macro-economic perspective. As a step to a micro-level approach studies like Fuest/Hemmelgarn/Ramb (2007) or Devereux/Loretz (2008) estimate hypothetical tax revenues under FA based on multi-jurisdictional entities' (MJE) unconsolidated financial reports. Due to data restrictions internal adjustment processes at the MJEs' level cannot be taken into account. An important part of these internal adjustments can be traced to the change of employment contracts. However, this aspect has been hitherto neglected in the discussion about the consequences of FA.

Accordingly, the goal of this paper is to show analytically the tax-induced distortions of compensation contracts caused by the introduction of FA. Doing so extends prior literature by including taxpayers' avoidance reactions. For this purpose we take a managerial accounting perspective instead of a public economics view. Consequently, we set up a principal-agent model of the LEN-type with agents in two different jurisdictions. ${ }^{8}$ Although we restrict our model to managerial remuneration for ease of presentation, the results extend to all kinds of variable and performance-based compensation including

\footnotetext{
${ }^{7}$ See Ernst \& Young (2011). Bettendorf et al. (2011) state: “Overall, we find that the common base would only slightly increase GDP (by $0,1 \%$ ) and employment (by only $0.03 \%$ ), and does not improve economic efficiency." For an analysis of the CCCTB based on a CGE model see Bettendorf et al. (2010).

${ }^{8} \mathrm{LEN}$ is an acronym for linear agent's compensation function and linear production function, exponential agent's utility function and normally distributed noise terms, see e.g. Spremann (1987).
} 
overtime compensation, piece rate wages, cafeteria benefit plans, variable deferred compensation, and other bonuses and premia. Hence, variable compensation accounts for a substantial fraction of total payroll.

The main results of our paper are: Whereas separate taxation (ST) is neutral with respect to employment contracts, formula apportionment induces a twofold distortion. First, the requested effort in the low-tax (high-tax) jurisdiction is inefficiently high (low). Second, the relation of fixed and variable compensation is distorted in both jurisdictions, leading to an inefficient risk allocation between principal and agents. This inefficiencies are identified for the first time, because they can only be detected from the firm-level view. Further, our model confirms the well-known results that employment is shifted to the low-tax jurisdiction and that the magnitude of shifting activities increases with increasing tax rate differential. In total, MJEs' net profits increase, while gross profits decrease due to the mentioned employment contract inefficiencies. This implies that total tax revenues decrease.

The contribution of this paper is to extend prior literature by focusing on a hitherto neglected aspect of FA. To our knowledge the impact of FA has not yet been analyzed in a principal-agent setting. Therefore, the effects of FA on managerial incentives and remuneration contracts are still unknown. In contrast to the existing FA literature we focus on payroll rather than the size of the workforce as the relevant apportionment factor. Even for immobile labor, the crucial factor payroll can be variable. ${ }^{9}$ If payroll is included in

\footnotetext{
${ }^{9}$ For a confirming view see Navaretti et al. (2003).
} 
the apportionment formula, both the level and the composition of management compensation are affected, altering incentives for managerial effort. However, focusing on the second-best case would still underestimate the reach of the considered tax incentives. The more pronounced results of the first-best case can be transferred to any kind of fixed compensation. Consequently, a switch from ST to FA impacts profits, even for MJEs without internal transactions.

Although a broad theoretical literature on FA exists, most papers take a political or a macro-economic view rather than a detailed firm-level perspective. ${ }^{10}$ An important issue is the optimal design of the apportionment formula, affecting, among others, the relative importance of wages for the tax allocation. ${ }^{11}$ Further, investment and production distortions have been considered under an FA regime. ${ }^{12}$ Among the few FA studies considering firm-specific properties of MJEs, like decentralization, delegation, and incentivisation, Nielsen/Raimondos-Møller/Schjelderup (2008) show that decision structures are influenced by tax parameters. Martini/Niemann/Simons (2012) prove that the effects of FA on production and investment decisions crucially depend on the accounting system in place and the mechanism defining how taxes are allocated to the subsidiaries of a MJE. Beyond FA, another important aspect is the incentivisation of subsidiaries' managements (see Bertrand/Mullainathan 2000, 2001) especially in the case of decentralization.

Riedel (2011) compares the consequences of separate accounting and FA on wages en-

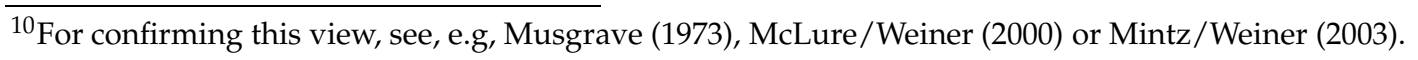

${ }^{11}$ See, e.g., McLure (1981), Shackelford/Slemrod (1998), Anand/Sansing (2000), Hellerstein/McLure (2004), Fox/Murray/Luna (2005).

${ }^{12}$ See Gordon/Wilson (1986) for the case of marginal investments.
} 
dogenously bargained by labor unions. She finds that under FA an increase in the domestic tax rate causes an increase in the foreign workers' salary. This result is related to our finding, where payroll and effort are shifted to the low-tax jurisdiction. However, our model differs from Riedel's in two important aspects: We integrate incentive problems and allow for differing productivity parameters between the two countries, whereas Riedel (2011) focuses on wage bargaining and considers symmetric workforces. Further, the research perspective differs fundamentally: We focus on tax planning considerations of a corporate decision maker whereas Riedel (2011) follows a tax competition perspective.

Summing up, the literature on FA has not yet analyzed the effects of FA resulting from internal decision processes of MJEs. By focussing on the demand for managerial effort and its distortions resulting from FA, this paper closes the existing research gap.

The remainder of the paper is organized as follows: In section 2 we introduce the general assumptions and explain the setup of the principal-agent model. In section 3 we analyze the first-best case, meaning that the agents' efforts are observable. In detail we focus on a case without taxes as benchmark, a case with ST (as currently practiced) and a case under FA. The same cases are analyzed in section 4 for the second-best case. This means that agents' efforts are unobservable, so that incentivisation becomes an issue besides tax planning. In section 5 we present a combination of the first-best case and the second-best case following the idea that distance to the headquarter matters from an incentive perspective. Section 6 summarizes the results, derives tax policy implications and 
suggests some extensions for future research.

\section{LEN Model setup}

In a multi-jurisdictional entity with a decentralized organizational structure the headquarter (principal) delegates managing the subsidiaries to several independent managers

(agents). The principal offers appropriate compensation contracts to the agents inducing the desired effort levels. We assume two agents to be located in two different jurisdictions with different tax rates. The risk-neutral principal maximizes the expected total profit net of compensation payments and taxes.

To keep the analysis as simple as possible, we assume that the MJE is not engaged in intra-firm transactions. This assumption means that the agents do not interact with each other or with the principal (apart from the compensation contract). Therefore, we can neglect the determination of arm's-length transfer prices. Accordingly, all distortions are attributable to FA.

Both agents are risk-averse and are characterized by negative-exponential utility functions. They accept their individual contract offers only if their reservation utilities are met as ensured by the participation constraints. Further, the agents are effort-averse indicated by multiplicatively separable disutility of effort. With observable efforts (first-best case), the principal forces the agents to provide the desired effort level. With unobservable efforts (second-best case), output-based compensation contracts motivate the agents to deliver the appropriate effort levels. Formally, this is modelled by the incentive con- 
straints.

The principal's objective function (1) is the expected difference of gross profits $x_{i}$, less the agents' compensations $w_{i}$, where $i=1,2$ symbolizes country $i$. The principal's objective function before taxes, $\Pi(\cdot)$, reads:

$$
\Pi\left(x_{i}, w_{i}\right)=\sum_{i=1}^{2} E\left[x_{i}-w_{i}\right],
$$

The agents' efforts $a_{i}$ affect the local profits in a linear manner, i.e., $x_{i}\left(a_{i}\right)=k_{i} a_{i}+\varepsilon_{i}$, where $k_{i}$ represents agent i's productivity. The noise terms $\varepsilon_{i}$ are normally distributed with an expected value of zero and a variance of $\sigma_{i}^{2}$. Assuming linear compensation contracts with fixed payments $f_{i}$ and variable compensation components related to local output $x_{i}$ by bonus coefficients $\pi_{i}$, i.e., $w_{i}=f_{i}+\pi_{i} x_{i}$, (1) can be written as:

$$
\Pi\left(\pi_{i}, f_{i}\right)=\sum_{i=1}^{2}\left(1-\pi_{i}\right) k_{i} a_{i}-f_{i}
$$

For observable efforts (first-best case) incentivization is not needed so that the bonus coefficients are zero: $\pi_{i}^{F B}=0$. Otherwise (second-best case), the bonus coefficients are strictly positive, $\pi_{i}^{S B}>0$

The participation constraints (3) ensure that the agents' expected utilities from their individual wage $w_{i}$ less the costs of effort $c_{i}\left(a_{i}\right)$ grant at least the reservation utilities $\bar{u}_{i}$. The agents' degrees of risk aversion are captured by the Arrow-Pratt measures $r_{i}$; the effort aversions are represented by $c_{i}\left(a_{i}\right)=\gamma_{i} \frac{a_{i}^{2}}{2}$, with $\gamma_{i}>0$ as individual effort cost parameters. Because of the LEN assumptions the agents' utilities can be represented by 
the according certainty equivalents. Hence, the participation constraints are:

$$
C E_{i}\left[U_{i}\left(\pi_{i}, f_{i}, a_{i}\right)\right]=\underbrace{f_{i}+\pi_{i} k_{i} a_{i}}_{E\left[w_{i}\right]}-\gamma_{i} \frac{a_{i}^{2}}{2}-\frac{r_{i}}{2} \pi_{i}^{2} \sigma_{i}^{2} \geq \bar{u}_{i}
$$

where $U_{i}(\cdot)$ denotes agent $i$ 's utility function and $\bar{u}_{i}$ represents the reservation wage. For simplicity we assume $\bar{u}_{i}=0$ throughout the paper.

If effort is unobservable the incentive constraints (4) ensure that the agents choose the individual effort levels that maximize their certainty equivalents:

$$
a_{i}^{*}=\operatorname{argmax}_{a_{i}} C E_{i}\left[U_{i}\left(\pi_{i}, f_{i}, a_{i}\right)\right]
$$

In case of observable effort (first-best case) the principal-agent problem is defined by (2) and (3), i.e., the incentive constraints are omitted. In case of unobservable efforts (secondbest), the problem is defined by (2)-(4).

The introduction of taxes requires additional assumptions. First, we assume proportional taxation of the principal's tax base at the nominal tax rate $t_{i}$ in jurisdiction $i$. Without loss of generality, we assume country $i=2$ to be the high-tax jurisdiction, i.e., $t_{2}>t_{1}$. Second, the principal's tax base is either based on separate taxation (ST) or on formula apportionment (FA). Under ST, each jurisdiction $i$ taxes the local gross profit $x_{i}$ less local remuneration costs $w_{i}$. Under FA, the global tax base is defined as the difference of total gross profits $\sum_{i} x_{i}$ less total remuneration costs $\sum_{i} w_{i}$. This global tax base is allocated to the two countries in accordance with an apportionment formula as shown in the following section. Third, to focus on the effects of a corporate tax regime switch we assume 
that the agents' remunerations are not taxable. ${ }^{13}$ Since taxation at the principal's level does not directly affect the agents' remunerations, the participation constraints (3) and the incentive constraints (4) remain unchanged.

\section{First-best case}

Our analysis distinguishes three cases:

1. First-best case ${ }^{14}$ without taxes

2. First-best case with ST

\section{First-best case with FA}

In the first-best case without taxes the solution of the agency problem is straightforward. The principal maximizes expected net profit $\Pi_{F B}=k_{1} a_{1}+k_{2} a_{2}-\frac{\gamma_{1} a_{1}^{2}}{2}-\frac{\gamma_{2} a_{2}^{2}}{2}$ by forcing each agent to provide the optimal effort level $a_{i}^{F B *}=\frac{k_{i}}{\gamma_{i}}$. By assumption, the principal can perfectly observe the exerted efforts. Thus, no incentivisation is needed. The agents are compensated for their efforts by fixed payments solving the participation constraints (3) with equality, i.e., $w_{i}^{F B}=f_{i}^{F B *}=\frac{\gamma_{i} a_{i}^{2}}{2}$. This implies that the agents' net remunerations are equal to the reservation wages of zero. Inserting the optimal effort levels $a_{i}^{*}$ into the objective function (2) gives the principal's optimal expected net profit $\Pi_{F B}^{*}=\frac{k_{1}^{2}}{2 \gamma_{1}}+\frac{k_{2}^{2}}{2 \gamma_{2}}$.

\footnotetext{
${ }^{13}$ This assumption will be relaxed in section 4.3 .

${ }^{14}$ In accordance with the agency literature we define the first-best case as the case with observable effort.
} 
Under ST each jurisdiction taxes its firm's net profit independently and separately from the other jurisdiction. This means that the local tax base is defined as $T B_{i}^{S T}=x_{i}-w_{i}$. As we assume the absence of intra-firm transactions, transfer prices are not needed to separate the entities' profits. Consequently, the principal's objective function slightly changes to $\Pi_{F B}^{S T}=\left(1-t_{1}\right)\left(k_{1} a_{1}-\frac{\gamma_{1} a_{1}^{2}}{2}\right)+\left(1-t_{2}\right)\left(k_{2} a_{2}-\frac{\gamma_{1} a_{1}^{2}}{2}\right)$. As the effort levels are still independent $\left(\frac{\partial^{2} \Pi_{F B}^{S T}}{\partial a_{1} \partial a_{2}}=0\right)$, the principal's choice of the optimal effort levels is unaffected by taxation. Thus, the desired optimal effort levels and the corresponding remunerations are identical to the first-best case without taxes. The optimal profit is reduced proportionally by the local tax rates, i.e., $\Pi_{F B}^{*}=\left(1-t_{1}\right) \frac{k_{1}^{2}}{2 \gamma_{1}}+\left(1-t_{2}\right) \frac{k_{2}^{2}}{2 \gamma_{2}}$. Consequently, the principal's financial objective is taxed implying that taxation is neutral with respect to the principal's choice of the effort level.

FA means that the worldwide tax base, $T B=x_{1}+x_{2}-w_{1}-w_{2}$, is allocated to the respective jurisdiction $i$ by means of an apportionment formula. Each jurisdiction applies its local tax rate $t_{i}$ to its fraction of the worldwide tax base, $T B_{i}^{F A}$. In general, the apportionment formula weights $j=1, \ldots, J$ apportionment factors by factor-specific weights $\lambda_{j}$, with $\sum_{j=1}^{J} \lambda_{j}=1 .{ }^{15}$ For each factor the realization within a given jurisdiction, $\phi_{j}^{i}$, is compared to the sum of the factor realizations in all participating jurisdictions:

$$
T B_{i}^{F A}=\left(\sum_{j=1}^{J} \lambda_{j} \frac{\phi_{j}^{i}}{\sum_{k} \phi_{j}^{k}}\right) T B
$$

\footnotetext{
${ }^{15}$ See e.g. Eichner/Runkel (2008) analyzing the effects of different formula factors.
} 
We consider a special case with two participating jurisdictions and payroll as the only apportionment factor $(J=1) \cdot{ }^{16}$ In this case, the local tax base simplifies to:

$$
T B_{i}^{F A}=\frac{w_{i}}{\sum_{j} w_{j}} T B=\frac{w_{i}}{w_{1}+w_{2}}\left(x_{1}+x_{2}-w_{1}-w_{2}\right)
$$

Substituting into (1) yields the principal's objective function under FA:

$$
\Pi^{F A}\left(x_{i}, w_{i}\right)=\left(1-t_{1} \frac{w_{1}}{w_{1}+w_{2}}-t_{2} \frac{w_{2}}{w_{1}+w_{2}}\right) \sum_{i=1}^{2} E\left[x_{i}-w_{i}\right]
$$

Since the agents' remunerations are tax-exempt by assumption, the participation constraints and the incentive constraints under FA are identical to the no-tax case. Using the resulting remunerations $w_{i}^{F B}=f_{i}^{F B *}=\frac{\gamma_{i} a_{i}^{2}}{2}$ leads to the principal's objective function as a function of the effort levels: ${ }^{17}$

$$
\Pi_{F B}^{F A}\left(a_{i}\right)=E\left[\left(1-\sum_{i=1}^{2} t_{i} \frac{\frac{\gamma_{i} a_{i}^{2}}{2}}{\sum_{j=1}^{2} \frac{\gamma_{j} a_{j}^{2}}{2}}\right) \sum_{i=1}^{2}\left(k_{i} a_{i}-\frac{\gamma_{i} a_{i}^{2}}{2}\right)\right]
$$

Rearranging terms gives:

$$
\Pi_{F B}^{F A}\left(a_{i}\right)=\left(1-t_{1}\right)\left[k_{1} a_{1}+k_{2} a_{2}-\gamma_{1} \frac{a_{1}^{2}}{2}-\gamma_{2} \frac{a_{2}^{2}}{2}\right] \overbrace{-\underbrace{\left(t_{2}-t_{1}\right) \gamma_{2} \frac{a_{2}^{2}}{2}}_{>0} \underbrace{\left[\frac{k_{1} a_{1}+k_{2} a_{2}}{\gamma_{1} \frac{a_{1}^{2}}{2}+\gamma_{2} \frac{a_{2}^{2}}{2}}-1\right]}_{\alpha}}^{\delta\left(a_{1}, a_{2}\right)}
$$

The first term in brackets in (9) represents the worldwide pre-tax profit. If both tax rates were equal to $t_{1}$ then the first product would give the worldwide after-tax profit. The

\footnotetext{
${ }^{16}$ The German local business tax is an example for a single-factor formula based on wages, see Büttner/Riedel/Runkel (2011). Riedel (2010) uses payroll as the only apportionment factor, too.

${ }^{17}$ For simplicity, we only consider uncorrelated risks, i.e., $\operatorname{Cov}\left(\sigma_{1}, \sigma_{2}\right)=0$.
} 
overbraced term $\delta(\cdot)$ accounts for the additional tax payment due to the tax rate differential. Inspecting (9) shows that $\alpha>0$ holds presupposed the total gross profit is positive. Hence, taxpayers shift profits from the high-tax jurisdiction to the low-tax jurisdiction to exploit tax rate differentials. This is achieved by reducing $a_{2}$ and/or by increasing $a_{1}$. If both tax rates are identical, $\delta\left(a_{1}, a_{2}\right)$ in (9) vanishes. The same holds for the optimality conditions for the effort levels, see (10) and (11), implying that the regimes ST and FA are equivalent.

As can be inferred from the partial derivatives (10) and (11) the conditions for optimal efforts under FA differ from ST. The optimality conditions in the first-best case without taxes are $k_{i}-\gamma_{i} a_{i}=0$. The second term $\frac{\partial \alpha}{\partial a_{i}}$ reflects the distortion following from tax planning considerations.

$$
\begin{aligned}
& \frac{\partial \Pi_{F B}^{F A}\left(a_{1}, a_{2}\right)}{\partial a_{1}}=\left(1-t_{1}\right)\left(k_{1}-\gamma_{1} a_{1}\right)+\frac{\partial \delta}{\partial a_{1}} \\
& \frac{\partial \Pi_{F B}^{F A}\left(a_{1}, a_{2}\right)}{\partial a_{2}}=\left(1-t_{1}\right)\left(k_{2}-\gamma_{2} a_{2}\right)+\frac{\partial \delta}{\partial a_{2}}
\end{aligned}
$$

Due to this effort shifting the net profit under FA is always higher than under ST. This can be shown in three steps: First, given the optimal effort levels from the ST case the net profits under ST and FA coincide. ${ }^{18}$ Second, we prove in Propositions 1 and 2 in appendix A that $\frac{\partial \delta}{\partial a_{1}}>0$ and $\frac{\partial \delta}{\partial a_{2}}<0$ holds true. Third, by adjusting the desired effort levels the principal can shift profit from the high-tax to the low-tax jurisdiction. As a result, the optimal efforts under FA are $a_{1}^{F A}>a_{1}^{S T}$ in the low-tax jurisdiction and $a_{2}^{F A}<a_{2}^{S T}$ in the

\footnotetext{
${ }^{18} \mathrm{~A}$ formal proof is provided in Proposition 3 in appendix A.
} 
high-tax jurisdiction. In contrast to the ST case the agents' effort levels are interdependent: $\frac{\partial^{2} \Pi_{F B}^{F A}}{\partial a_{1} \partial a_{2}} \neq 0$

Since analytical solutions are typically infeasible, the economic effects are illustrated by a set of examples exhibiting representative scenarios: ${ }^{19}$

1. The agents' productivities and effort aversions are identical $\left(k_{1}=k_{2}\right.$ and $\left.\gamma_{1}=\gamma_{2}\right)$, see Table 6 in appendix A. In this symmetric case all effort differentials are due to FA.

2. The agent in the high-tax jurisdiction is more productive and more expensive than the other agent $\left(k_{2}>k_{1}\right.$ and $\left.\gamma_{2}>\gamma_{1}\right)$, see Table 7 in appendix A. This more realistic setting incorporates the common expectation that high-tax jurisdictions are on average more productive, but incur higher costs. For small tax rate differentials the principal requests higher effort from the more productive agent. For high tax rate differentials profit shifting incentives become more important than productivities.

The effort effects of ST and FA are summarized in figure 1, based on the parameters $k_{1}=1, k_{2}=5 ; \gamma_{1}=\gamma_{2}=1, t_{1}=0.25, t_{2}=0.6$

*** Insert Figure 1 around here ${ }^{* * *}$

\footnotetext{
${ }^{19}$ As the objective function (8) involves sixth-degree polynomials there are typically no closed-form solutions for the optimization problem under FA. Apart from the settings presented in the appendix, other parameter combinations yield similar economic results. These additional numerical results will be provided upon request.
} 
Figure 1 displays level curves of the principal's net profit as functions of effort combinations $\left(a_{1} ; a_{2}\right)$. The point $a^{S T *}$ denotes the optimal effort combination under ST. The set enclosed by the corresponding level curve represents all effort constellations inducing higher total net profits under FA than under ST. It should be noted that the sets enclosed by the lower level curves are not necessarily convex. However, environments closer to the FA effort optimum, $a^{F A *}$, form a convex set. Due to the convex effort costs the distances between the level curves in the upper right part decrease, reflecting a steeper slope of the objective function. The following results can be summarized:

1. The point $a^{S T *}$ in Figure 1 shows that maximizing the total profit requires reducing $a_{2}$ and increasing $a_{1}$.

2. In the FA optimum the sum of efforts can be higher or lower than under ST, depending on the parameter setting under consideration. For $k_{1}=k_{2}=\gamma_{1}=\gamma_{2}=1$ (case 1), for instance, introducing FA reduces total effort. By contrast, for $k_{1}=1, k_{2}=$ $5, \gamma_{1}=1, \gamma_{2}=2$ (case 2 ) total effort increases due to FA. ${ }^{20}$ A second glance at Table 7 highlights the rationale underlying the latter effect. Because agent 2 is more productive than agent 1 , the principal prefers shifting profits by increasing $a_{1}$ instead of reducing $a_{2}$. However, with increasing tax rates $t_{2}$ production in the high-tax jurisdiction becomes more and more unattractive. Finally, the principal prefers to reduce $a_{2}$ for profit shifting. The opposite effects occur when $\gamma$ varies over the countries.

3. The optimal efforts depend on the tax rate differential, i.e., they are functions of

\footnotetext{
${ }^{20}$ Remember that under ST the sum of efforts is $\sum_{i} \frac{k_{i}}{\gamma_{i}}$.
} 
$\frac{1-t_{1}}{t_{2}-t_{1}}$ as can be inferred from rearranging the partial derivative (10). This effect is exhibited in Table 6: The effort allocation for the tax rate combinations $\left(t_{1} ; t_{2}\right)=$ $(0.2 ; 0.6),(0.4 ; 0.7),(0.6 ; 0.8),(0.8 ; 0.9)$ all lead to identical effort levels $\left(a_{1}^{*} ; a_{2}^{*}\right)=$ $(1.178 ; 0.702)$.

4. As a surprising result that does not depend on the parameter setting, even MJEs without internal transactions are affected by FA.

For deeper insight consider the numerical example presented in Figure 1, basing on the following data: $k_{1}=1, k_{2}=5, \gamma_{1}=\gamma_{2}=1, t_{1}=0.25, t_{2}=0.6$. The variables $T_{i}^{C}$ represent corporate tax revenues, i.e., taxes paid by the principal in jurisdiction $i$.

\begin{tabular}{lccc}
\hline variable & ST & FA & difference of ST and FA \\
\hline$\left(f_{1} ; f_{2}\right)$ & $(0.5 ; 12.5)$ & $(2.669 ; 9.223)$ & $(+2.169 ;-3.277)$ \\
$\left(a_{1}^{*} ; a_{2}^{*}\right)$ & $(1.0 ; 5.0)$ & $(2.311 ; 4.295)$ & $(+1.311,-0.705)$ \\
$\left.\Pi_{F B}\right|_{a_{i}^{*} ; t_{i}=0}$ & 13.0 & 11.893 & -1.107 \\
$\Pi_{F B}^{S T} ; \Pi_{F B}^{F A}$ & 5.375 & 5.691 & +0.316 \\
$\left(T_{1}^{C} ; T_{2}^{C}\right)$ & $(0.125 ; 7.5)$ & $(0.667 ; 5.534)$ & $(+0.542 ;-1.966)$ \\
\hline
\end{tabular}

Table 1: Comparision of ST and FA in the first-best case

The principal's net profit increases by almost $6 \%$ due to the introduction of FA. Empirical evidence suggests that these additional tax planning opportunities will be exploited by 
taxpayers. ${ }^{21}$ As the optimal effort levels under FA differ from those under ST and in the no-tax case, the pre-tax profit in the FA optimum falls short of the pre-tax profit in the ST optimum. Combined with the increasing net profit, this implies that worldwide taxes decrease under FA compared to ST as is confirmed in the last row of Table 1. Under ST increasing the tax rate results in a proportional increase of tax revenues irrespective of which jurisdiction is considered. Under FA, however, tax rate increases in one country result in disproportionately low tax revenue increases in this country.

\section{Second-best case}

In contrast to the previous section we assume that managerial efforts are not observable. In a cross-border context, this setting is representative for foreign subsidiaries under imperfect supervision by the headquarter in the domestic country.

With respect to the tax systems we consider the same variations as in the first-best case, namely:

1. Second-best case without taxes

2. Second-best case with ST

3. Second-best case with FA

\footnotetext{
${ }^{21}$ See, e.g., Klassen/Lang/Wolfson (1993), Klassen/Shackelford (1998), Mintz/Smart (2004).
} 


\subsection{Second-best case without taxes}

Assuming non-observability of the agents' actions means that the agency problem is now defined by (2)-(4). The incentive constraints indicate that the agents need to be motivated by performance-related compensation contracts.

Maximizing the agents' certainty equivalents $C E_{i}$ as given in (3) yields the optimal effort

levels $\frac{\partial C E_{i}}{\partial a_{i}}=0 \Leftrightarrow a_{i}^{*}=\pi_{i} \frac{k_{i}}{\gamma_{i}}$. Inserting $a_{i}^{*}$ into the participation constraints (3) and solving for the expected remunerations $w_{i}$ gives:

$$
w_{i}=f_{i}+\frac{\pi_{i}^{2} k_{i}^{2}}{\gamma_{i}}=\bar{u}_{i}+\frac{\pi_{i}^{2} k_{i}^{2}}{2 \gamma_{i}}+\frac{r_{i}}{2} \pi_{i}^{2} \sigma_{i}^{2}=\frac{\pi_{i}^{2}}{2}\left(\frac{k_{i}^{2}}{\gamma_{i}}+r_{i} \sigma_{i}^{2}\right)
$$

Considering the expected compensations, the principal's objective function only depends on the bonus coefficients $\pi_{i}$ :

$$
\Pi_{S B}\left(\pi_{i}\right)=\sum_{i=1}^{2} \frac{k_{i}^{2}}{\gamma_{i}} \pi_{i}-\frac{1}{2}\left(\frac{k_{i}^{2}}{\gamma_{i}}+r_{i} \sigma_{i}^{2}\right) \pi_{i}^{2}
$$

By computing $\frac{\partial^{2} \Pi_{S B}}{\partial \pi_{1} \partial \pi_{2}}=0$, it can be easily shown that the optimal bonus coefficients $\pi_{1}$ and $\pi_{2}$ do not interact. Differentiating $\Pi_{S B}\left(\pi_{i}\right)$ with respect to $\pi_{i}$ generates the optimal bonus coefficients:

$$
\pi_{i}^{*}=\frac{\frac{k_{i}^{2}}{\gamma_{i}}}{\frac{k_{i}^{2}}{\gamma_{i}}+r_{i} \sigma_{i}^{2}}<1
$$

Thus, the optimal effort levels are:

$$
a_{i}^{*}=\pi_{i} \frac{k_{i}}{\gamma_{i}}=\frac{\frac{k_{i}^{3}}{\gamma_{i}^{2}}}{\frac{k_{i}^{2}}{\gamma_{i}}+r_{i} \sigma_{i}^{2}}
$$

Similarly, the fixed payments $f_{i}$ result as:

$$
f_{i}^{*}=-\frac{1}{2}\left(\frac{\frac{k_{i}^{2}}{\gamma_{i}}}{\frac{k_{i}^{2}}{\gamma_{i}}+r_{i} \sigma_{i}^{2}}\right)^{2}\left(\frac{k_{i}^{2}}{\gamma_{i}}-r_{i} \sigma_{i}^{2}\right)
$$


Finally, the principal's expected optimal net profit amounts to:

$$
\Pi_{S B}^{*}=\frac{1}{2} \sum_{i=1}^{2} \frac{\frac{k_{i}^{4}}{\gamma_{i}^{2}}}{\frac{k_{i}^{2}}{\gamma_{i}}+r_{i} \sigma_{i}^{2}}
$$

\subsection{Second-best case with profit taxation at the principal's level}

By assumption the agents' remunerations are tax-exempt. Since the participation constraints and the incentive constraints are identical to the case without taxes, the optimal efforts and optimal remuneration parameters remain unchanged. ST at the principal's level can be easily integrated by multiplying the local profits by the after-tax factor $\left(1-t_{i}\right)$ :

$$
\Pi_{S B}^{S T}=\frac{1}{2} \sum_{i=1}^{2}\left(1-t_{i}\right)\left(\frac{\frac{k_{i}^{4}}{\gamma_{i}^{2}}}{\frac{k_{i}^{2}}{\gamma_{i}}+r_{i} \sigma_{i}^{2}}\right)
$$

Like in the first-best case taxation at the principal's level is neutral with respect to the effort levels.

We assume that the agents' variable compensations are still based on local gross profits $x_{i}$ rather than global gross profits $x_{1}+x_{2}$. Consequently, the agents' participation constraints and incentive constraints remain unchanged as compared to (3) and (4). Only the principal's objective function is affected by FA. It reads:

$$
\Pi_{S B}^{F A}\left(\pi_{i}, f_{i}, t_{i}\right)=\left(1-\sum_{i=1}^{2} t_{i} \frac{\pi_{i} x_{i}+f_{i}}{\sum_{j=1}^{2} \pi_{j} x_{j}+f_{j}}\right) \sum_{i=1}^{2} E\left[\left(1-\pi_{i}\right) x_{i}-f_{i}\right]
$$

Technically, the optimization calculus proceeds similarly to the ST case: The agents' optimal effort levels as functions of the bonus coefficients $\pi_{i}$ are derived from the incentive 
constraints (4): $a_{i}^{*}\left(\pi_{i}\right)=\pi_{i} \frac{k_{i}}{\gamma_{i}}$. As the agents maximize their respective certainty equivalent their (potentially different) risk attitudes are recognized automatically. Inserting the optimal effort functions $a_{i}^{*}\left(\pi_{i}\right)$ into the participation constraints (3) leads to the fixed payments that are also functions of the bonus coefficients:

$$
f_{i}\left(\pi_{i}\right)=-\frac{\pi_{i}^{2}}{2}\left(\frac{k_{i}^{2}}{\gamma_{i}}-r_{i} \sigma_{i}^{2}\right)
$$

Further, the principal's gross profit $x_{1}+x_{2}$ is a function of the bonus coefficients, with $x_{i}\left(\pi_{i}\right)=\pi_{i} \frac{k_{i}^{2}}{\gamma_{i}}$. Substituting the resulting expressions into the principal's objective function (19) leads to a function that only depends on $\pi_{1}$ and $\pi_{2}$ :

$$
\Pi_{S B}^{F A}\left(\pi_{i}, f_{i}, t_{i}\right)=\left[1-\sum_{i=1}^{2} t_{i} \frac{\frac{1}{2} \pi_{i}^{2}\left(\frac{k_{i}^{2}}{\gamma_{i}}+r_{i} \sigma_{i}^{2}\right)}{\sum_{j=1}^{2} \frac{1}{2} \pi_{j}^{2}\left(\frac{k_{j}^{2}}{\gamma_{j}}+r_{j} \sigma_{j}^{2}\right)}\right] \sum_{i=1}^{2} \frac{k_{i}^{2}}{\gamma_{i}} \pi_{i}-\frac{1}{2} \pi_{i}^{2}\left(\frac{k_{i}^{2}}{\gamma_{i}}+r_{i} \sigma_{i}^{2}\right)
$$

As in the first-best case, maximizing $\Pi_{S B}^{F A}$ with respect to $\pi_{1}$ and $\pi_{2}$ does not permit analytical solutions for the optimal bonus coefficients. To describe the emerging effects, numerical results are provided in Tables $8-13$. We can observe the following results:

1. Like in the first-best case with FA the principal has an incentive to shift remuneration and thus effort to the low-tax jurisdiction. Compared to the no-tax case this causes effort inefficiencies in both countries. Given the tax rate $t_{1}$ higher tax rate differential imply higher (lower) bonus coefficients and hence efforts in the low-tax (high-tax) jurisdiction. 
2. Shifting remuneration can be realized by increasing fixed or variable payments or both. Fixed payments do not motivate the agent to provide additional effort. Therefore, the principal prefers increasing variable payments over increasing fixed payments. This effect contradicts the EU's aim to curb excessive bonus payments for managers. Because the principal can motivate effort via the bonus coefficient, in the low-tax (high-tax) jurisdiction $\pi_{i}$ increases (decreases) compared to ST. Managerial effort and remuneration is shifted by means of the bonus coefficient to the low-tax jurisdiction. Compared to the second-best case without taxation the principal induces a higher (lower) effort level in the low-tax (high-tax) jurisdiction, ${ }^{22}$ implying inefficient effort levels in both countries that typically do not compensate each other.

3. Like in the ST case the fixed compensation is only used to meet the participation constraint with equality. Allowing for slack would contradict the principal's profit maximization objective.

4. Compared to ST the principal's net profit increases. In contrast to the European Commission's tax policy objectives, incentives for tax planning still exist under FA and can be even larger than under ST.

5. Although the bonus coefficients and hence the effort levels are driven by tax rate differentials the agents' productivities $k_{i}$ in the respective countries (Tables $11-13$ ) and different risk attitudes (Tables 9 -10) must not be neglected. If a highly productive agent is located in the low-tax jurisdiction incentive effect and tax effect have

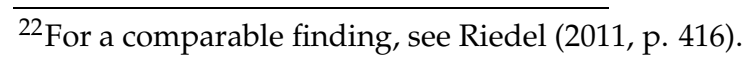


the same direction. Moreover, if the highly productive agent is located in the hightax jurisdiction (Table $11-13$ ), the bonus coefficient in the low-tax, low-productivity jurisdiction reacts most sensitive to tax rate changes.

6. Depending on the parameter constellation the sum of optimal efforts increases or decreases due to FA.

For illustrating the arising harmful economic effects of FA consider the following numerical example with the parameters $k_{1}=1, k_{2}=5, \gamma_{1}=\gamma_{2}=1, \sigma_{1}=\sigma_{2}=1, r_{1}=r_{2}=$ $2, t_{1}=0.25, t_{2}=0.6$

*** Insert Figure 2 around here $* * *$

Figure 2 displays the level curves of the principal's objective function and the optimal bonus coefficients under ST and FA. Obviously, the income shifting incentives resulting from FA are very similar to the first-best case.

For more detailed insights consider Table 2.

The compensation parameters and effort levels under ST as shown in Table 2 coincide with the results of the no-tax case, because the agents' compensations are tax-exempt. Comparing columns ST and FA, the following results can be observed: For shifting taxes to the low-tax jurisdiction, the principal substantially increases the bonus coefficient in country 1 and slightly reduces the bonus coefficient in country 2 as stated in the results 1 . and 2. described above. As an important result, the bonus coefficient $\pi_{1}$ exceeds $100 \%$ while still granting a positive fixed payment. This means that more than the entire pre-tax 


\begin{tabular}{lccc}
\hline variable & ST & FA & difference of ST and FA \\
\hline$\left(\pi_{1} ; \pi_{2}\right)$ & $(0.333 ; 0.926)$ & $(1.011 ; 0.835)$ & - \\
$\left(f_{1} ; f_{2}\right)$ & $(0.0556 ;-9.859)$ & $(0.511 ;-8.014)$ & - \\
$\left(w_{1} ; w_{2}\right)$ & $(0.167 ; 11.574)$ & $(1.533 ; 9.407)$ & $(+1.366 ;-2.167)$ \\
$\left(a_{1}^{*} ; a_{2}^{*}\right)$ & $(0.333 ; 4.630)$ & $(1.011 ; 4.174)$ & $(+0.678 ;-0.456)$ \\
$\Pi_{S B} \mid a_{i}^{*}, t_{i}=0$ & 11.741 & 10.940 & -0.801 \\
$\Pi_{S B}^{S T} ; \Pi_{S B}^{F A}$ & 4.755 & 4.912 & +0.157 \\
$\left(T_{1}^{C} ; T_{2}^{C}\right)$ & $(0.0417 ; 6.944)$ & $(0.383 ; 5.644)$ & $(+0.3413 ;-1.3)$ \\
\hline
\end{tabular}

Table 2: Comparision of ST and FA in the second-best case

profit in the low-tax jurisdiction is awarded to the respective agent. By contrast, a bonus coefficient exceeding 1 cannot occur under ST, as can be inferred from (14). This case indicates that the principal motivates agent 1 to exert an inefficiently high effort requiring a total compensation that turns a local profit into a local loss. Given the cross-border lossoffset under FA, this loss is overcompensated by the resulting tax reduction. These findings are confirmed by the total expected remunerations $w_{i}$. Due to the switch to FA, agent 1's remuneration increases almost tenfold. While the performance-based compensation in the low-tax jurisdiction always increases due to FA, the fixed payment can change in either direction depending on the relation of the parameters in (20).

The change of the principal's profit before and after taxes demonstrates the tax-induced 
distortions. Given the remuneration packages and the resulting efforts, the pre-tax profit under FA is smaller than under ST. However, the after-tax profit is higher under FA due to profit shifting as mentioned in results 4 . and 5. Overall, FA causes a tax relief, but at the expense of increased effort inefficiency.

Comparing the results of the first-best case as depicted in Table 1 and the second-best case as depicted in Table 2 shows similar effects. As the main difference of the two cases, the consequences of FA are mitigated in the second-best case.

In the model variations presented above the principal's tax payments do not affect the agent's remuneration. Nevertheless, the agents' effort levels become interdependent due to the tax allocation mechanism applied by FA. This interdependence would still be aggravated if the principal's tax payment was allocated to the agents. In this case, an additional interdependency would arise. The agents' incentive constraint would now contain the

allocation formula $\frac{w_{i}}{\sum_{i} w_{i}}$. Accordingly, each agent would have to consider his own output uncertainty as well as the uncertainty stemming from the other agent's output function. Although the risk would still be normally distributed in this case, the compensation function would become non-linear implying that the LEN model would be no longer feasible.

\subsection{Second-best case with profit and wage taxation}

As a robustness check we integrate the hitherto neglected wage taxation. Integrating wage taxation at the agents' level requires a modification of the principal-agent program, because the participation constraints (22) and the incentive constraints (23) are affected by 
wage taxation, but not by corporate taxation. We assume that the entire remuneration is subject to the constant wage tax rate $\tau_{i}$. The monetary equivalent of effort disutility is non-deductible. Further, the after-tax reservation utility is denoted by $\bar{u}_{i}^{\tau} \cdot{ }^{23}$ The performance measure for the variable compensation is still defined by the gross profit before remuneration costs $x_{i}$. The modified participation constraints then read:

$$
C E_{i}^{\tau}\left[U_{i}\left(\pi_{i}, f_{i}, a_{i}\right)\right]=\left(1-\tau_{i}\right)\left(f_{i}+\pi_{i} k_{i} a_{i}\right)-\gamma_{i} \frac{a_{i}^{2}}{2}-\left(1-\tau_{i}\right)^{2} \frac{r_{i}}{2} \pi_{i}^{2} \sigma_{i}^{2} \geq \bar{u}_{i}^{\tau}
$$

The after-tax incentive constraints are given by:

$$
\frac{\partial C E_{i}^{\tau}}{\partial a_{i}}=0 \Leftrightarrow a_{i}^{*}=\left(1-\tau_{i}\right) \pi_{i} \frac{k_{i}}{\gamma_{i}}
$$

According to these modifications the principal's objective function becomes:

$$
\Pi_{S B}^{S T, \tau}\left(\pi_{i}\right)=\sum_{i=1}^{2}-\frac{\bar{u}_{i}^{\tau}}{1-\tau_{i}}+\left(1-\tau_{i}\right) \frac{k_{i}^{2}}{\gamma_{i}} \pi_{i}-\frac{1}{2}\left(1-\tau_{i}\right)\left(\frac{k_{i}^{2}}{\gamma_{i}}+r_{i} \sigma_{i}^{2}\right) \pi_{i}^{2}
$$

The partial derivatives of (24) with respect to $\pi_{i}$ show that wage taxation does not alter the optimal bonus coefficients, but reduces the optimal effort levels proportionally under ST. ${ }^{24}$ Further, the fixed compensation increases, the principal's gross and net profit decrease monotonically with increasing wage tax rates.

Given that optimal effort levels change due to wage taxation additional distortive effects of FA are likely. Formally, FA only affects the principal's objective function, but not

\footnotetext{
${ }^{23}$ For the impact of the wage tax on the after-tax reservation utility see Niemann (2008, p. 284).

${ }^{24}$ See Niemann (2008).
} 
the constraints (22) and (23):

$$
\begin{aligned}
\Pi_{S B}^{F A, \tau}\left(\pi_{i}, f_{i}, t_{i}\right)= & {\left[1-\sum_{i=1}^{2} t_{i} \frac{\frac{\bar{u}_{i}^{\tau}}{1-\tau_{i}}+\frac{1}{2}\left(1-\tau_{i}\right) \pi_{i}^{2}\left(\frac{k_{i}^{2}}{\gamma_{i}}+r_{i} \sigma_{i}^{2}\right)}{\sum_{j=1}^{2} \frac{\bar{u}_{j}^{\tau}}{1-\tau_{j}}+\frac{1}{2}\left(1-\tau_{j}\right) \pi_{j}^{2}\left(\frac{k_{j}^{2}}{\gamma_{j}}+r_{j} \sigma_{j}^{2}\right)}\right] } \\
& \cdot \sum_{i=1}^{2} \frac{k_{i}^{2}}{\gamma_{i}}\left(1-\tau_{i}\right) \pi_{i}-\frac{\bar{u}_{i}^{\tau}}{1-\tau_{i}}-\frac{1}{2}\left(1-\tau_{i}\right) \pi_{i}^{2}\left(\frac{k_{i}^{2}}{\gamma_{i}}+r_{i} \sigma_{i}^{2}\right)
\end{aligned}
$$

Like in the case without wage taxation, closed-form solutions are infeasible for FA. Therefore, we consider two variations of our standard numerical example. In the first variation the corporate tax rate differential $t_{1}-t_{2}$ and the wage tax rate differential $\tau_{1}-\tau_{2}$ have the same algebraic sign. In the second variation the differentials have opposite algebraic signs. Again, the parameters are: $k_{1}=1, k_{2}=5, \gamma_{1}=\gamma_{2}=1, \sigma_{1}=\sigma_{2}=1, r_{1}=r_{2}=$ $2, t_{1}=0.25, t_{2}=0.6$. For the wage tax rates we assume $\tau_{1}=0.25$ and $\tau_{2}=0.6$.

The example emphasizes that wage taxation reduces the optimal effort levels under both tax regimes, but the qualitative results derived so far are confirmed. Wage taxation tends to reduce the excessive labor demand in the low-tax jurisdiction, mitigating the inefficiency. By contrast, the inefficiency is aggravated in the high-tax jurisdiction, because the demand for labor shrinks further. Comparing Tables 2 and 3 shows that wage taxation does not affect the bonus coefficients under ST. As the wage tax increases the costs of managerial labor, the requested efforts and hence total remunerations are reduced, as can be observed from rows $\left(w_{1} ; w_{2}\right)$ and $\left(a_{1}^{*} ; a_{2}^{*}\right)$. The last three rows of Table 3 display the profit tax revenues $T_{i}^{C}$, the wage tax revenues $T_{i}^{W}$, and total tax revenues $T_{i}$ under ST and FA. As expected, the low-tax jurisdiction increases tax revenues dramatically, while the high-tax jurisdiction suffers from substantial revenue losses. 


\begin{tabular}{lccc}
\hline variable & ST & FA & difference of ST and FA \\
\hline$\left(\pi_{1} ; \pi_{2}\right)$ & $(0.333 ; 0.926)$ & $(0.855 ; 0.811)$ & - \\
$\left(f_{1} ; f_{2}\right)$ & $(0.0417 ;-3.944)$ & $(0.274 ;-3.028)$ & - \\
$\left(w_{1} ; w_{2}\right)$ & $(0.125 ; 4.630)$ & $(0.823 ; 3.555)$ & $(+0.698 ;-1.075)$ \\
$\left(a_{1}^{*} ; a_{2}^{*}\right)$ & $(0.25 ; 1.852)$ & $(0.641 ; 1.623)$ & $(+0.391 ;-0.229)$ \\
$\left.\Pi_{S B}\right|_{a_{i}^{*}, t_{i}=0}$ & 4.755 & 4.377 & -0.378 \\
$\Pi_{S B}^{S T, \tau} ; \Pi_{S B}^{F A, \tau}$ & 1.946 & 2.039 & +0.093 \\
$\left(T_{1}^{C} ; T_{2}^{C}\right)$ & $(0.0313 ; 2.778)$ & $(0.206 ; 2.133)$ & $(+0.174 ;-0.645)$ \\
$\left(T_{1}^{W} ; T_{2}^{W}\right)$ & $(0.0313 ; 2.778)$ & $(0.206 ; 2.133)$ & $(+0.174 ;-0.645)$ \\
$\left(T_{1} ; T_{2}\right)$ & $(0.0625 ; 5.555)$ & $(0.411 ; 4.266)$ & $(+0.349 ;-1.290)$ \\
\hline
\end{tabular}

Table 3: Comparison of ST and FA with wage taxation at $\tau_{1}=0.25, \tau_{2}=0.6$

With opposite algebraic signs of the tax rate differentials, the effects slightly change. For this example we assume $\tau_{1}=0.6$ and $\tau_{2}=0.25$. In this case, the revenue losses of jurisdiction 2 are not as severe as in the previous example as can be observed from the last three rows of Table 4 .

\section{A combination of first-best case and second-best case}

In the previous sections, we assumed that the incentive problem is either present or not in both agency relationships. For estimating the consequences of FA on different legal 


\begin{tabular}{lccc}
\hline result & ST & FA & difference of ST and FA \\
\hline$\left(\pi_{1} ; \pi_{2}\right)$ & $(0.333 ; 0.926)$ & $(1.190 ; 0.855)$ & - \\
$\left(f_{1} ; f_{2}\right)$ & $(0.0222 ;-7.395)$ & $(0.283 ;-6.308)$ & - \\
$\left(w_{1} ; w_{2}\right)$ & $(0.0667 ; 8.681)$ & $(0.850 ; 7.406)$ & $(+0.07833 ;-1.275)$ \\
$\left(a_{1}^{*} ; a_{2}^{*}\right)$ & $(0.133 ; 3.472)$ & $(0.476 ; 3.207)$ & $(+0.343 ;-0.265)$ \\
$\left.\Pi_{S B}\right|_{a_{i}^{*}, t_{i}=0}$ & 8.747 & 8.256 & -0.491 \\
$\Pi_{S B}^{S T, \tau} ; \Pi_{S B}^{F A, \tau}$ & 3.522 & 3.600 & +0.078 \\
$\left(T_{1}^{C} ; T_{2}^{C}\right)$ & $(0.0167 ; 5.208)$ & $(0.213 ; 4.443)$ & $(+0.196 ;-0.765)$ \\
$\left(T_{1}^{W} ; T_{2}^{W}\right)$ & $(0.040 ; 2.170)$ & $(0.510 ; 1.851)$ & $(+0.470 ;-0.319)$ \\
$\left(T_{1} ; T_{2}\right)$ & $(0.0567 ; 7.378)$ & $(0.723 ; 6.295)$ & $(+0.666 ;-1.084)$ \\
\hline
\end{tabular}

Table 4: Comparision of ST and FA with wage taxation at $\tau_{1}=0.6, \tau_{2}=0.25$

types of firms first-best and second-best case are combined subsequently. The business interpretation of this combination is that one part of the firm is run by the owner himself (first-best) whereas the other part of the MJE is managed by an employed manager (second-best). This setting represents a typical situation of small and medium-sized enterprises extending their business beyond their domestic country.

Hence, in our example the principal is located in the high-tax, high-productivity jurisdiction and extends his business to a low-tax, low-productivity jurisdiction. Technically, for ST the example results presented below can be generated by simply combining the 
analytical solutions from the previous two sections. Under FA it should be taken into account that two different decision variables enter the principal's objective function, namely effort $a_{2}$ for the first-best part (high-tax jurisdiction) and the bonus coefficient $\pi_{1}$ for the second-best part of the problem. Nevertheless, the optimization procedure is quite similar. In particular, the principal's objective function changes to:

$$
\begin{aligned}
\Pi_{F B / S B}^{F A}= & {\left[1-t_{1} \frac{\bar{u}_{1}+\frac{1}{2} \pi_{1}^{2}\left(\frac{k_{1}^{2}}{\gamma_{1}}+r_{1} \sigma_{1}^{2}\right)}{\bar{u}_{1}+\frac{1}{2} \pi_{1}^{2}\left(\frac{k_{1}^{2}}{\gamma_{1}}+r_{1} \sigma_{1}^{2}\right)+\frac{\gamma_{2} a_{2}^{2}}{2}}-t_{2} \frac{\frac{\gamma_{2} a_{2}^{2}}{2}}{\bar{u}_{1}+\frac{1}{2} \pi_{1}^{2}\left(\frac{k_{1}^{2}}{\gamma_{1}}+r_{1} \sigma_{1}^{2}\right)+\frac{\gamma_{2} a_{2}^{2}}{2}}\right] } \\
& \cdot\left(\frac{k_{i}^{2}}{\gamma_{1}} \pi_{1}-\bar{u}_{1}-\frac{1}{2} \pi_{1}^{2}\left(\frac{k_{1}^{2}}{\gamma_{1}}+r_{1} \sigma_{1}^{2}\right)+k_{2} a_{2}-\frac{\gamma_{2} a_{2}^{2}}{2}\right)
\end{aligned}
$$

As analytical solutions of the maximization problem are infeasible, further insights can be gained from the continued numerical example. Again, the parameters are: $k_{1}=1, k_{2}=$ $5, \gamma_{1}=\gamma_{2}=1, \sigma_{1}=\sigma_{2}=1, r_{1}=r_{2}=2, t_{1}=0.25, t_{2}=0.6$. Wage taxation is neglected in this model variation, because the resulting effects correspond to those mentioned in section 4.3 .

Due to the absence of an incentive problem in jurisdiction 2 the results depicted in Table 5 are only partly comparable to those in Table 2 . Hence, total pre-tax and after-tax profits are higher. With respect to the effects of FA, this example is also a combination of first-best and second-best: The absolute values of the FA-induced differences are between those in Table 1 (first-best) and in Table 2 (second-best). In a qualitative sense, however, all results derived in the previous versions of our model are confirmed.

Assuming that the principal is located in the low-tax jurisdiction and keeping all other parameters constant generates similar results. ${ }^{25}$

\footnotetext{
${ }^{25}$ As no qualitative changes occur, the alternative setting is not presented here.
} 


\begin{tabular}{lccc}
\hline variable & ST & FA & difference of ST and FA \\
\hline$\left(\pi_{1} ; \pi_{2}\right)$ & $(0.333 ;-)$ & $(1.032 ;-)$ & - \\
$\left(f_{1} ; f_{2}\right)$ & $(0.0556 ; 12.5)$ & $(0.532 ; 10.225)$ & - \\
$\left(w_{1} ; w_{2}\right)$ & $(0.167 ; 12.5)$ & $(1.596 ; 10.225)$ & $(+1.429 ;-2.275)$ \\
$\left(a_{1}^{*} ; a_{2}^{*}\right)$ & $(0.333 ; 5)$ & $(1.032 ; 4.522)$ & $(+0.699 ;-0.478)$ \\
$\left.\Pi_{S B}\right|_{a_{i}^{*}, t_{i}=0}$ & 12.667 & 11.821 & -0.846 \\
$\Pi_{S B}^{S T} ; \Pi_{S B}^{F A}$ & 5.125 & 5.287 & +0.162 \\
$\left(T_{1}^{C} ; T_{2}^{C}\right)$ & $(0.0416 ; 7.5)$ & $(0.399 ; 6.135)$ & $(+0.3575 ;-1.365)$ \\
\hline
\end{tabular}

Table 5: Comparision of ST and FA in the combined case (principal located in the high-tax country)

\section{Summary and conclusion}

This paper presents an analytical principal-agent model that investigates the impact of FA on the demand for managerial effort and the design of compensation contracts in MJEs. To our knowledge this model is the first to combine an agency setting with FA-based multinational taxation. The results provide an impression about the adjustments of the demand for managerial labor that can be expected after the introduction of FA. This finding extends to all kinds of variable/performance-based compensation instruments and hereby covers a substantial fraction of total payroll.

Using a LEN model without taxes as a reference case we distinguish between observ- 
able (first-best case) and unobservable (second-best case) managerial effort. Then we integrate taxation and compare the effects of ST versus FA in the principal-agent model. Implementing ST at the principal's level, it is easy to show that a corporate tax is neutral with respect to the design of remuneration contracts. Taxation just reduces profits proportionally without altering the agents' optimal effort levels or compensation parameters. As in the no-tax case the principal simply faces two separate incentive problems that are not linked by ST and that can be solved analytically.

In order to focus on the effects of FA on the level and composition of managerial compensation we assume a simple apportionment formula with payroll as the single apportionment factor. Since FA is effectively a tax on the factors included in the apportionment formula, taxpayers have an incentive to shift payroll from the high-tax to the low-tax jurisdiction. Even if the workforce is immobile, payroll is (to some extent) variable and can be shifted by adjusting the requested managerial efforts and/or compensation parameters. This firm-level view contrasts with the perspective commonly held in the public finance literature, see, e.g. Runkel/Schjelderup (2011).

Introducing FA substantially complicates the principal's optimization problem. If the agents' efforts are observable, the principal has to solve two separate agency problems under separate taxation (ST). By contrast, FA offers income shifting incentives. Therefore, the effort incentive problems become interdependent due to FA. While the principal reduces demanded effort and thus compensation for the agent located in the high-tax jurisdiction, the opposite occurs for the agent located in the low-tax jurisdiction. Overall, 
the principal's net profit increases due to profit shifting resulting from FA. In the secondbest case, with unobservable efforts, the results are qualitatively similar to the first-best case: The principal's gross profit decreases, the net profit increases and managerial effort and remuneration are shifted from the high-tax to the low-tax jurisdiction. The principal's reaction to the introduction of FA is mitigated compared to the first-best case due to the trade-off between tax planning and incentivisation. In spite of the one-period setting and the simple one-factor apportionment formula, FA does not permit analytical expressions for the optimal effort levels and the optimal remuneration parameters. Numerical simulations show that the income shifting incentives induced by FA distort the demand for managerial effort and the composition of the compensation package. In special cases under unobservable effort it can be shown that more than $100 \%$ of the pre-tax profit in the low-tax jurisdiction is given to the respective agent just to exploit the corporate tax rate differential, emphasizing that FA might foster excessive compensation. Our examples reveal that MJEs without internal transactions and no profit shifting potential under ST gain additional tax planning potential due to FA.

Since the optimal effort levels and compensation parameters under FA differ from the optimal pre-tax values, pre-tax profits of MJEs under FA always decrease compared to ST while after-tax profits increase. These individual gains at the principal's level are reached at the expense of social inefficiencies, see also Bettendorf et al. (2011).

The incentive problem mitigates the FA-induced distortions although the qualitative results in the second-best case are the same as in the first-best case. In addition to the 
tax planning problem the trade-off between motivation and risk-taking has to be solved in the second-best case. Thus, tax considerations are less significant than in the first-best case.

Under FA, the demand for labor and the corporate tax rate are negatively related whereas productivity and demand for labor are positively related. However, the dominant effect cannot be easily predicted. Thus, the effects of tax rate differentials under FA cannot be analyzed without regard to productivity coefficients. ${ }^{26}$

Our model is subject to several limitations. Since we utilize a LEN model, the wellknown critique applies to our model as well. E.g., the linearity assumption restricts the set of feasible compensation contracts. Moreover, we focus on a one-factor apportionment formula, whereas real-world FA systems typically include three apportionment factors (payroll, sales, and capital). However, we do not expect qualitative changes given additional apportionment factors apart from payroll. ${ }^{27}$

Our model analyzes only MJEs without internal transactions. This assumption is restrictive, because it avoids the costly determination of arm's-length transfer prices that is the main reason for the ongoing debate about the implementation of FA in the EU. Of course, MJEs with internal transactions would lose some tax planning potential due to the partial abolishment of transfer pricing. However, the additional tax planning potential provided by FA would also apply to those MJEs.

\footnotetext{
${ }^{26}$ Riedel (2011, p. 415) shares this point of view.

${ }^{27}$ See, e.g., Riedel (2011, p. 415) or Martini/Niemann/Simons (2012).
} 


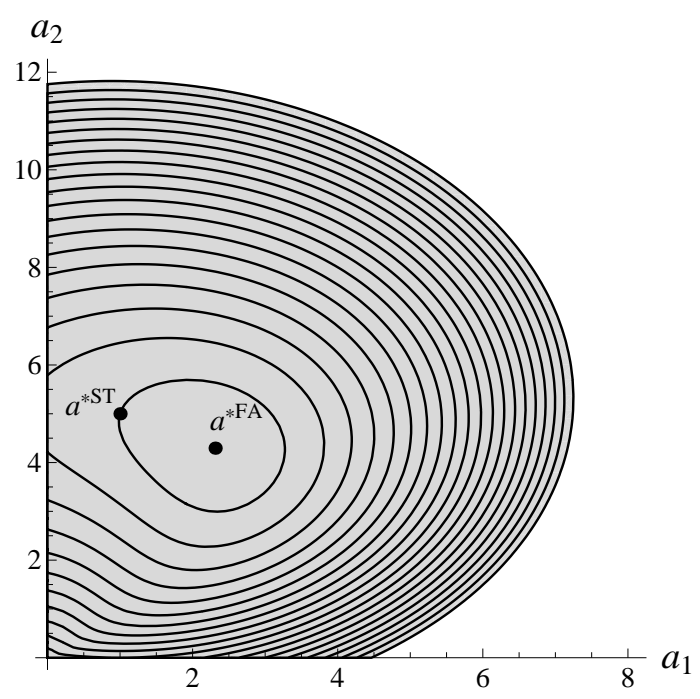

Figure 1: Level curves of the principal's objective function in the first-best case under FA

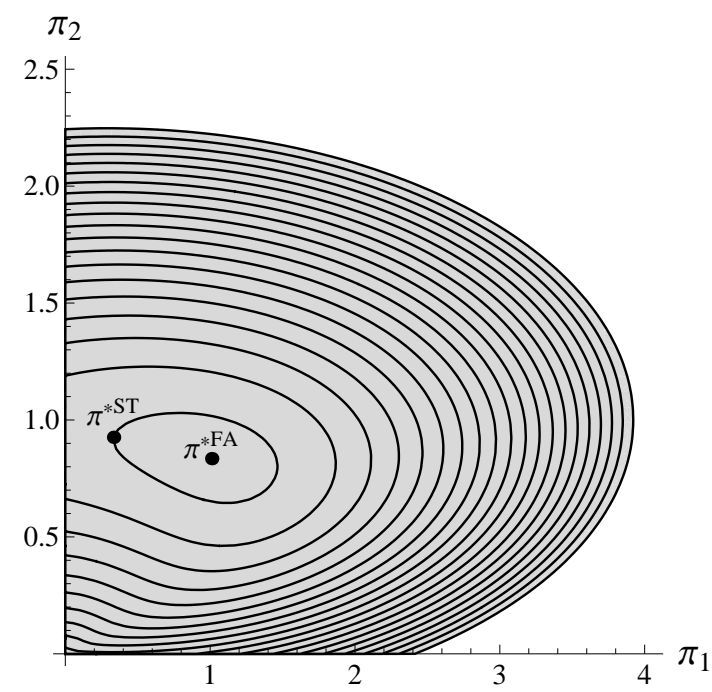

Figure 2: Level curves of the principal's objective function in the second-best case under 


\section{Appendix A: Proofs}

Proposition 1. The partial derivative of the principal's objective function with respect to $a_{1},(10)$, is positive at the positions $a_{i}=\frac{k_{i}}{\gamma_{i}}$.

Proof:

$$
\frac{\partial \delta}{\partial a_{1}}=-\left(t_{2}-t_{1}\right) \gamma_{2} \frac{a_{2}^{2}}{2}\left[\frac{k_{1}\left(\gamma_{1} \frac{a_{1}^{2}}{2}+\gamma_{2} \frac{a_{2}^{2}}{2}\right)-\left(k_{1} a_{1}+k_{2} a_{2}\right) \gamma_{1} a_{1}}{\left(\gamma_{1} \frac{a_{1}^{2}}{2}+\gamma_{2} \frac{a_{2}^{2}}{2}\right)^{2}}\right]
$$

For $\frac{\partial \Pi}{\partial a_{1}}>0$ it suffices to show that the numerator of the fraction in brackets is negative:

$$
\begin{array}{r}
\frac{1}{2} k_{1} \gamma_{1} a_{1}^{2}+\frac{1}{2} k_{1} \gamma_{2} a_{2}^{2}-k_{1} \gamma_{1} a_{1}^{2}-k_{2} \gamma_{1} a_{1} a_{2}<0 \\
\Leftrightarrow \frac{1}{2} k_{1}\left(\gamma_{2} a_{2}^{2}-\gamma_{1} a_{1}^{2}\right)<k_{2} \gamma_{1} a_{1} a_{2}
\end{array}
$$

Inserting $a_{i}=\frac{k_{i}}{\gamma_{i}}$ yields:

$$
\frac{1}{2}\left(\frac{k_{2}^{2}}{\gamma_{2}}-\frac{k_{1}^{2}}{\gamma_{1}}\right)<\frac{k_{2}^{2}}{\gamma_{2}}
$$

Proposition 2. The partial derivative of the principal's objective function with respect to $a_{2},(11)$, is negative at the positions $a_{i}=\frac{k_{i}}{\gamma_{i}}$.

Proof:

$\frac{\partial \delta}{\partial a_{2}}=-\left(t_{2}-t_{1}\right)\left\{\gamma_{2} a_{2}\left[\frac{k_{1} a_{1}+k_{2} a_{2}}{\gamma_{1} \frac{a_{1}^{2}}{2}+\gamma_{2} \frac{a_{2}^{2}}{2}}-1\right]+\gamma_{2} \frac{a_{2}^{2}}{2}\left[\frac{k_{2}\left(\gamma_{1} \frac{a_{1}^{2}}{2}+\gamma_{2} \frac{a_{2}^{2}}{2}\right)-\left(k_{1} a_{1}+k_{2} a_{2}\right) \gamma_{2} a_{2}}{\left(\gamma_{1} \frac{a_{1}^{2}}{2}+\gamma_{2} \frac{a_{2}^{2}}{2}\right)^{2}}\right]\right\}$

Replacing $a_{i}$ by $\frac{k_{i}}{a_{i}}$ and cancelling out yields:

$$
\frac{\partial \delta}{\partial a_{2}}=-\left(t_{2}-t_{1}\right)\left[k_{2}-\frac{\frac{1}{2} k_{2}^{3}}{\gamma_{2}\left(\frac{k_{1}^{2}}{\gamma_{1}}+\frac{k_{2}^{2}}{\gamma_{2}}\right)}\right]
$$

Unifying the terms in brackets completes the proof:

$$
\frac{\partial \delta}{\partial a_{2}}=-\left(t_{2}-t_{1}\right) \frac{k_{2}^{3}-\frac{1}{2} k_{2}^{3}+k_{2} k_{1}^{2}}{\gamma_{2}\left(\frac{k_{1}^{2}}{\gamma_{1}} \frac{k_{2}^{2}}{\gamma_{2}}\right)}<0
$$


Proposition 3. Inserting the optimal compensation of the first-best case with ST, i.e., $\pi=0$ and $f_{i}=\gamma_{i} \frac{a_{i}^{2}}{2}$ into the profit function (8) of the first-best case under FA yields the same total profit $\Pi^{F B *}=\left(1-t_{1}\right) \frac{k_{1}^{2}}{2 \gamma_{1}}+\left(1-t_{2}\right) \frac{k_{2}^{2}}{2 \gamma_{2}}$.

Proof:

$$
\Pi_{F B}^{S T}\left(a_{1, F B}^{S T *}, a_{2, F B}^{S T *}, w_{1, F B}^{S T *}, w_{2, F B}^{S T *}\right)=\Pi_{F B}^{F A}\left(a_{1, F B}^{S T *}, a_{2, F B}^{S T *}, w_{1, F B}^{S T *}, w_{2, F B}^{S T *}\right)
$$

Applying the most general formulations gives:

$\Leftrightarrow\left(1-t_{1}\right)\left(x_{1}-w_{1}\right)+\left(1-t_{2}\right)\left(x_{2}-w_{2}\right)=\left(1-t_{1}\right)\left(x_{1}-w_{1}+x_{2}-w_{2}\right)-\left(t_{2}-t_{1}\right) w_{2}\left(\frac{x_{1}+x_{2}}{w_{1}+w_{2}}-1\right)$

Canceling identical terms and simplifying gives:

$$
\Leftrightarrow\left(t_{2}-t_{1}\right)\left(x_{2}-w_{2}\right)=\left(t_{2}-t_{1}\right) w_{2}\left(\frac{x_{1}+x_{2}}{w_{1}+w_{2}}-1\right)
$$

Exploiting that $w_{i}=\frac{x_{i}}{2}$ generates:

$$
\Leftrightarrow x_{2}\left(\frac{x_{1}}{2}+\frac{x_{2}}{2}\right)=\frac{x_{2}}{2}\left(x_{1}+x_{2}\right),
$$

which completes the proof.

\section{Appendix B: Numerical results in the first-best case}




\begin{tabular}{|c|c|c|c|c|c|c|c|c|c|}
\hline$t_{1} \mid t_{2}$ & & 0.2 & 0.3 & 0.4 & 0.5 & 0.6 & 0.7 & 0.8 & 0.9 \\
\hline 01 & $\left(a_{1}^{*} ; a_{2}^{*}\right)$ & $(1.054 ; 0.939)$ & $(1.103 ; 0.870)$ & $(1.141 ; 0.799)$ & $(1.168 ; 0.733)$ & $(1.186 ; 0.673)$ & $(1.197 ; 0.620)$ & $(1.203 ; 0.575)$ & $(1.206 ; 0.535)$ \\
\hline 0.1 & $\Pi_{F B}^{F A}$ & 0.853 & 0.812 & 0.777 & 0.745 & 0.723 & 0.702 & 0.684 & 0.669 \\
\hline 0.2 & $\left(a_{1}^{*} ; a_{2}^{*}\right)$ & - & $(1.061 ; 0.930)$ & $(1.113 ; 0.852)$ & $(1.152 ; 0.774)$ & $(1.178 ; 0.702)$ & $(1.193 ; 0.639)$ & $(1.202 ; 0.585)$ & $(1.206 ; 0.539)$ \\
\hline 0.2 & $\Pi_{F B}^{F A}$ & - & 0.753 & 0.714 & 0.680 & 0.653 & 0.631 & 0.612 & 0.596 \\
\hline 0.3 & $\left(a_{1}^{*} ; a_{2}^{*}\right)$ & - & & $(1.069 ; 0.920)$ & $(1.126 ; 0.829)$ & $(1.164 ; 0.742)$ & $(1.188 ; 0.665)$ & $(1.200 ; 0.600)$ & $(1.206 ; 0.546)$ \\
\hline 0.3 & $\Pi_{F B}^{F A}$ & - & - & 0.654 & 0.615 & 0.585 & 0.560 & 0.540 & 0.524 \\
\hline 0.4 & $\begin{array}{c}\left(a_{1}^{*} ; a_{2}^{*}\right) \\
\end{array}$ & - & - & - & $(1.080 ; 0.905)$ & $(1.141 ; 0.799)$ & $(1.178 ; 0.702)$ & $(1.197 ; 0.620)$ & $(1.205 ; 0.554)$ \\
\hline 0.5 & $\left(a_{1}^{*} ; a_{2}^{*}\right)$ & & & - & 0.554 & $\begin{array}{c}0.518 \\
(1.094 ; 0.884)\end{array}$ & $\begin{array}{c}0.490 \\
(1.158 ; 0.759)\end{array}$ & $\begin{array}{c}0.468 \\
(1.191 ; 0.651)\end{array}$ & $\begin{array}{c}0.451 \\
(1.204 ; 0.566)\end{array}$ \\
\hline 0.5 & $\Pi_{F B}^{F A}$ & - & - & - & - & 0.455 & 0.422 & 0.397 & 0.378 \\
\hline 0.6 & $\begin{array}{c}\left(a_{1}^{*} ; a_{2}^{*}\right) \\
\prod_{F B}^{F A}\end{array}$ & - & - & - & - & - & $\begin{array}{c}(1.113 ; 0.852) \\
0.357\end{array}$ & $\begin{array}{c}(1.178 ; 0.702) \\
0.327\end{array}$ & $\begin{array}{c}(1.202 ; 0.585) \\
0.306\end{array}$ \\
\hline 0.7 & $\begin{array}{c}\left(a_{1}^{*} ; a_{2}^{*}\right) \\
\Pi_{F B}^{F A}\end{array}$ & - & - & - & - & - & - & $\begin{array}{c}(1.141 ; 0.799) \\
0.259\end{array}$ & $\begin{array}{c}(1.197 ; 0.620) \\
0.234\end{array}$ \\
\hline 0.8 & $\begin{array}{c}\left(a_{1}^{*} ; a_{2}^{*}\right) \\
\Pi_{F B}^{F A}\end{array}$ & - & - & - & - & - & - & - & $\begin{array}{c}(1.178 ; 0.702) \\
0.163\end{array}$ \\
\hline
\end{tabular}

Table 6: Optimal results under FA: $k_{1}=1, k_{2}=1, \gamma_{1}=1, \gamma_{2}=1$ 


\begin{tabular}{|c|c|c|c|c|c|c|c|c|c|}
\hline$t_{1} \mid t_{2}$ & & 0.2 & 0.3 & 0.4 & 0.5 & 0.6 & 0.7 & 0.8 & 0.9 \\
\hline 01 & $\left(a_{1}^{*} ; a_{2}^{*}\right)$ & $(1.126 ; 2.471)$ & $(1.316 ; 2.414)$ & $(1.584 ; 2.299)$ & $(1.877 ; 2.110)$ & $(2.099 ; 1.890)$ & $(2.231 ; 1.686)$ & $(2.299 ; 1.513)$ & $(2.329 ; 1.370)$ \\
\hline 0.1 & $\Pi_{F B}^{F A}$ & 5.456 & 4.858 & 4.230 & 3.811 & 3.411 & 3.092 & 2.836 & 2.629 \\
\hline 0.2 & $\left(a_{1}^{*} ; a_{2}^{*}\right)$ & - & $(1.146 ; 2.466)$ & $(1.376 ; 2.392)$ & $(1.697 ; 2.236)$ & $(2 ; 2)$ & $(2.190 ; 1.759)$ & $(2.286 ; 1.553)$ & $(2.327 ; 1.386)$ \\
\hline & $\Pi_{F B}^{F A}$ & & 4.782 & 4.190 & 3.651 & 3.2 & 2.847 & 2.573 & 2.358 \\
\hline 0.3 & $\begin{array}{c}\left(a_{1}^{*} ; a_{2}^{*}\right) \\
\end{array}$ & - & & $(1.173 ; 2.459)$ & $(1.460 ; 2.357)$ & $(1.838 ; 2.140)$ & $(2.123 ; 1.859)$ & $(2.266 ; 1.608)$ & $(2.324 ; 1.408)$ \\
\hline 0.3 & $\Pi_{F B}^{F A}$ & - & - & 4.109 & 3.525 & 3.014 & 2.614 & 2.314 & 2.088 \\
\hline 0.4 & $\begin{array}{c}\left(a_{1}^{*} ; a_{2}^{*}\right) \\
\end{array}$ & - & - & - & $(1.211 ; 2.448)$ & $(1.584 ; 2.299)$ & $(2 ; 2)$ & $(2.231 ; 1.686)$ & $(2.318 ; 1.438)$ \\
\hline 0.5 & $\left(a_{1}^{*} ; a_{2}^{*}\right)$ & & & & 3.436 & $(1.271 ; 2.429)$ & $\begin{array}{c}2.4 \\
(1.764 ; 2.193)\end{array}$ & $\begin{array}{c}2.061 \\
(2.161 ; 1.805)\end{array}$ & $\begin{array}{c}1.818 \\
(2.308 ; 1.482)\end{array}$ \\
\hline 0.5 & $\Pi_{F B}^{F A}$ & - & - & - & - & 2.764 & 2.220 & 1.819 & 1.551 \\
\hline 0.6 & $\begin{array}{c}\left(a_{1}^{*} ; a_{2}^{*}\right) \\
\Pi_{F B}^{F A}\end{array}$ & - & - & - & - & - & $\begin{array}{c}(1.376 ; 2.392) \\
2.095\end{array}$ & $\begin{array}{c}(2 ; 2) \\
1.6\end{array}$ & $\begin{array}{c}(2.286 ; 1.553) \\
1.287\end{array}$ \\
\hline 0.7 & $\begin{array}{c}\left(a_{1}^{*} ; a_{2}^{*}\right) \\
\prod_{F B}^{F A}\end{array}$ & - & - & - & - & - & - & $\begin{array}{c}(1.584 ; 2.299) \\
1.433\end{array}$ & $\begin{array}{c}(2.231 ; 1.686) \\
1.031\end{array}$ \\
\hline 0.8 & $\begin{array}{c}\left(a_{1}^{*} ; a_{2}^{*}\right) \\
\Pi_{F B}^{F A}\end{array}$ & - & - & - & - & - & - & - & $\begin{array}{c}(2 ; 2) \\
0.8\end{array}$ \\
\hline
\end{tabular}

Table 7: Optimal results under FA: $k_{1}=1, k_{2}=5, \gamma_{1}=1, \gamma_{2}=2$ 


\section{Appendix C: Numerical results in the second-best case}




\begin{tabular}{|c|c|c|c|c|c|c|c|c|c|}
\hline$t_{1} \mid t_{2}$ & & 0.2 & 0.3 & 0.4 & 0.5 & 0.6 & 0.7 & 0.8 & 0.9 \\
\hline 0.1 & $\begin{array}{c}f_{i} \\
\pi_{i} \\
\Pi_{S B}\end{array}$ & $\begin{array}{c}(0.0 ; 0.0) \\
(0.527 ; 0.469) \\
(0.426)\end{array}$ & $\begin{array}{c}(0.0 ; 0.0) \\
(0.551 ; 0.435) \\
(0.406)\end{array}$ & $\begin{array}{c}(0.0 ; 0.0) \\
(0.570 ; 0.400) \\
(0.389)\end{array}$ & $\begin{array}{c}(0.0 ; 0.0) \\
(0.584 ; 0.366) \\
(0.374)\end{array}$ & $\begin{array}{c}(0.0 ; 0.0) \\
(0.593 ; 0.336) \\
(0.362)\end{array}$ & $\begin{array}{c}(0.0 ; 0.0) \\
(0.598 ; 0.310) \\
(0.351)\end{array}$ & $\begin{array}{c}(0.0 ; 0.0) \\
(0.602 ; 0.287) \\
(0.342)\end{array}$ & $\begin{array}{c}(0.0 ; 0.0) \\
(0.603 ; 0.267) \\
(0.335)\end{array}$ \\
\hline 0.2 & $\begin{array}{c}f_{i} \\
\pi_{i} \\
\Pi_{S B}\end{array}$ & - & $\begin{array}{c}(0.0 ; 0.0) \\
(0.530 ; 0.465) \\
(0.377)\end{array}$ & $\begin{array}{c}(0.0 ; 0.0) \\
(0.557 ; 0.426) \\
(0.357)\end{array}$ & $\begin{array}{c}(0.0 ; 0.0)) \\
(0.576 ; 0.387) \\
(0.340)\end{array}$ & $\begin{array}{c}(0.0 ; 0.0)) \\
(0.589 ; 0.351) \\
(0.327)\end{array}$ & $\begin{array}{c}(0.0 ; 0.0) \\
(0.597 ; 0.320) \\
(0.315)\end{array}$ & $\begin{array}{c}(0.0 ; 0.0)) \\
(0.601 ; 0.293) \\
(0.306)\end{array}$ & $\begin{array}{c}(0.0 ; 0.0) \\
(0.603 ; 0.270) \\
(0.298)\end{array}$ \\
\hline 0.3 & $\begin{array}{c}f_{i} \\
\pi_{i} \\
\Pi_{S B} \\
\end{array}$ & - & - & $\begin{array}{c}(0.0 ; 0.0) \\
(0.535 ; 0.460) \\
(0.327)\end{array}$ & $\begin{array}{c}(0.0 ; 0.0) \\
(0.563 ; 0.415) \\
(0.308)\end{array}$ & $\begin{array}{c}(0.0 ; 0.0) \\
(0.582 ; 0.371) \\
(0.292)\end{array}$ & $\begin{array}{c}(0.0 ; 0.0) \\
(0.594 ; 0.332) \\
(0.280)\end{array}$ & $\begin{array}{c}(0.0 ; 0.0) \\
(0.600 ; 0.300) \\
(0.27)\end{array}$ & $\begin{array}{c}(0.0 ; 0.0) \\
(0.603 ; 0.273) \\
(0.262)\end{array}$ \\
\hline 0.4 & $\begin{array}{c}f_{i} \\
\pi_{i} \\
\Pi_{S B}\end{array}$ & - & - & - & $\begin{array}{c}(0.0 ; 0.0) \\
(0.540 ; 0.452) \\
(0.277)\end{array}$ & $\begin{array}{c}(0.0 ; 0.0) \\
(0.570 ; 0.400) \\
(0.259)\end{array}$ & $\begin{array}{c}(0.0 ; 0.0) \\
(0.589 ; 0.351) \\
(0.245)\end{array}$ & $\begin{array}{c}(0.0 ; 0.0) \\
(0.598 ; 0.310) \\
(0.234)\end{array}$ & $\begin{array}{c}(0.0 ; 0.0) \\
(0.603 ; 0.277) \\
(0.225)\end{array}$ \\
\hline 0.5 & $\begin{array}{c}f_{i} \\
\pi_{i} \\
\Pi_{S B} \\
\end{array}$ & - & - & - & - & $\begin{array}{c}(0.0 ; 0.0) \\
(0.547 ; 0.442) \\
(0.228)\end{array}$ & $\begin{array}{c}(0.0 ; 0.0) \\
(0.579 ; 0.379) \\
(0.211)\end{array}$ & $\begin{array}{c}(0.0 ; 0.0) \\
(0.595 ; 0.326) \\
(0.198)\end{array}$ & $\begin{array}{c}(0.0 ; 0.0) \\
(0.602 ; 0.283) \\
(0.189)\end{array}$ \\
\hline 0.6 & $\begin{array}{c}f_{i} \\
\pi_{i} \\
\Pi_{S B}\end{array}$ & - & - & - & - & - & $\begin{array}{c}(0.0 ; 0.0) \\
(0.557 ; 0.426) \\
(0.178)\end{array}$ & $\begin{array}{c}(0.0 ; 0.0) \\
(0.589 ; 0.351) \\
(0.136)\end{array}$ & $\begin{array}{c}(0.0 ; 0.0) \\
(0.601 ; 0.293) \\
(0.153)\end{array}$ \\
\hline 0.7 & $\begin{array}{c}f_{i} \\
\pi_{i} \\
\Pi_{S B}\end{array}$ & - & - & - & - & - & - & $\begin{array}{c}(0.0 ; 0.0) \\
(0.570 ; 0.400) \\
(0.130)\end{array}$ & $\begin{array}{c}(0.0 ; 0.0) \\
(0.598 ; 0.310) \\
(0.117)\end{array}$ \\
\hline 0.8 & $\begin{array}{c}f_{i} \\
\pi_{i} \\
\Pi_{S B}\end{array}$ & - & - & - & - & - & - & - & $\begin{array}{c}(0.0 ; 0.0) \\
(0.589 ; 0.351) \\
(0.082)\end{array}$ \\
\hline
\end{tabular}

Table 8: Optimal results case $1 \mathrm{a}: k_{1}=1, k_{2}=1, \gamma_{1}=1, \gamma_{2}=1, r_{1}=1, r_{2}=1, \sigma_{1}=1, \sigma_{2}=1$ 


\begin{tabular}{|c|c|c|c|c|c|c|c|c|c|}
\hline$t_{1} \mid t_{2}$ & & 0.2 & 0.3 & 0.4 & 0.5 & 0.6 & 0.7 & 0.8 & 0.9 \\
\hline 0.1 & $\begin{array}{c}f_{i} \\
\pi_{i} \\
\Pi_{S B}\end{array}$ & $\begin{array}{c}(0.0 ; 0.051) \\
(0.514 ; 0.184) \\
(0.306)\end{array}$ & $\begin{array}{c}(0.0 ; 0.043) \\
(0.525 ; 0.169) \\
(0.298)\end{array}$ & $\begin{array}{c}(0.0 ; 0.036) \\
(0.533 ; 0.155) \\
(0.291)\end{array}$ & $\begin{array}{c}(0.0 ; 0.0303) \\
(0.538 ; 0.142) \\
(0.286)\end{array}$ & $\begin{array}{c}(0.0 ; 0.026) \\
(0.542 ; 0.131) \\
(0.281)\end{array}$ & $\begin{array}{c}(0.0 ; 0.022) \\
(0.544 ; 0.122) \\
(0.274)\end{array}$ & $\begin{array}{c}(0.0 ; 0.019) \\
(0.545 ; 0.114) \\
(0.274)\end{array}$ & $\begin{array}{c}(0.0 ; 0.017) \\
(0.546 ; 0.106) \\
(0.271)\end{array}$ \\
\hline 0.2 & $\begin{array}{c}f_{i} \\
\pi_{i} \\
\Pi_{S B}\end{array}$ & - & $\begin{array}{c}(0.0 ; 0.050) \\
(0.516 ; 0.182) \\
(0.271)\end{array}$ & $\begin{array}{c}(0.0 ; 0.060) \\
(0.527 ; 0.165) \\
(0.260)\end{array}$ & $\begin{array}{c}(0.0 ; 0.034) \\
(0.535 ; 0.150) \\
(0.257)\end{array}$ & $\begin{array}{c}(0.0 ; 0.028) \\
(0.540 ; 0.137) \\
(0.252)\end{array}$ & $\begin{array}{c}(0.0 ; 0.004) \\
(0.543 ; 0.125) \\
(0.248)\end{array}$ & $\begin{array}{c}(0.0 ; 0.020) \\
(0.545 ; 0.116) \\
(0.244)\end{array}$ & $\begin{array}{c}(0.0 ; 0.017) \\
(0.546 ; 0.108) \\
(0.241)\end{array}$ \\
\hline 0.3 & $\begin{array}{c}f_{i} \\
\pi_{i} \\
\Pi_{S B} \\
\end{array}$ & - & - & $\begin{array}{c}(0.0 ; 0.048) \\
(0.518 ; 0.180) \\
(0.236)\end{array}$ & $\begin{array}{c}(0.0 ; 0.039) \\
(0.530 ; 0.161) \\
(0.229)\end{array}$ & $\begin{array}{c}(0.0 ; 0.031) \\
(0.537 ; 0.144) \\
(0.223)\end{array}$ & $\begin{array}{c}(0.0 ; 0.025) \\
(0.542 ; 0.130) \\
(0.218)\end{array}$ & $\begin{array}{c}(0.0 ; 0.021) \\
(0.544 ; 0.118) \\
(0.214)\end{array}$ & $\begin{array}{c}(0.0 ; 0.018) \\
(0.546 ; 0.108) \\
(0.211)\end{array}$ \\
\hline 0.4 & $\begin{array}{c}f_{i} \\
\pi_{i} \\
\Pi_{S B}\end{array}$ & - & - & - & $\begin{array}{c}(0.0 ; 0.047) \\
(0.520 ; 0.176) \\
(0.201)\end{array}$ & $\begin{array}{c}(0.0 ; 0.036) \\
(0.533 ; 0.155) \\
(0.194)\end{array}$ & $\begin{array}{c}(0.0 ; 0.028) \\
(0.540 ; 0.137) \\
(0.189)\end{array}$ & $\begin{array}{c}(0.0 ; 0.022) \\
(0.544 ; 0.122) \\
(0.185)\end{array}$ & $\begin{array}{c}(0.0 ; 0.018) \\
(0.545 ; 0.110) \\
(0.181)\end{array}$ \\
\hline 0.5 & $\begin{array}{c}f_{i} \\
\pi_{i} \\
\Pi_{S B} \\
\end{array}$ & - & - & - & - & $\begin{array}{c}(0.0 ; 0.044) \\
(0.523 ; 0.172) \\
(0.166)\end{array}$ & $\begin{array}{c}(0.0 ; 0.032) \\
(0.536 ; 0.147) \\
(0.160)\end{array}$ & $\begin{array}{c}(0.0 ; 0.024) \\
(0.543 ; 0.128) \\
(0.155)\end{array}$ & $\begin{array}{c}(0.0 ; 0.019) \\
(0.545 ; 0.112) \\
(0.152)\end{array}$ \\
\hline 0.6 & $\begin{array}{c}f_{i} \\
\pi_{i} \\
\Pi_{S B}\end{array}$ & - & - & - & - & - & $\begin{array}{c}(0.0 ; 0.041) \\
(0.527 ; 0.165) \\
(0.132)\end{array}$ & $\begin{array}{c}(0.0 ; 0.028) \\
(0.540 ; 0.137) \\
(0.126)\end{array}$ & $\begin{array}{c}(0.0 ; 0.020) \\
(0.545 ; 0.116) \\
(0.122)\end{array}$ \\
\hline 0.7 & $\begin{array}{c}f_{i} \\
\pi_{i} \\
\Pi_{S B}\end{array}$ & - & - & - & - & - & - & $\begin{array}{c}(0.0 ; 0.036) \\
(0.533 ; 0.155) \\
(0.097)\end{array}$ & $\begin{array}{c}(0.0 ; 0.022) \\
(0.544 ; 0.122) \\
(0.092)\end{array}$ \\
\hline 0.8 & $\begin{array}{c}f_{i} \\
\pi_{i} \\
\Pi_{S B}\end{array}$ & - & - & - & - & - & - & - & $\begin{array}{c}(0.0 ; 0.028) \\
(0.540 ; 0.137) \\
(0.063)\end{array}$ \\
\hline
\end{tabular}

Table 9: Optimal results case $1 \mathrm{~b}: k_{1}=1, k_{2}=1, \gamma_{1}=1, \gamma_{2}=1, r_{1}=1, r_{2}=1, \sigma_{1}=1, \sigma_{2}=4$ 


\begin{tabular}{|c|c|c|c|c|c|c|c|c|c|}
\hline$t_{1} \mid t_{2}$ & & 0.2 & 0.3 & 0.4 & 0.5 & 0.6 & 0.7 & 0.8 & 0.9 \\
\hline 0.1 & $\begin{array}{c}f_{i} \\
\pi_{i} \\
\Pi_{S B}\end{array}$ & $\begin{array}{c}(0.071 ; 0.0) \\
(0.217 ; 0.480) \\
(0.349)\end{array}$ & $\begin{array}{c}(0.084 ; 0.0) \\
(0.236 ; 0.453) \\
(0.269)\end{array}$ & $\begin{array}{c}(0.096 ; 0.0) \\
(0.253 ; 0.419) \\
(0.250)\end{array}$ & $\begin{array}{c}(0.107 ; 0.0) \\
(0.267 ; 0.383) \\
(0.234)\end{array}$ & $\begin{array}{c}(0.115 ; 0.0) \\
(0.276 ; 0.349) \\
(0.220)\end{array}$ & $\begin{array}{c}(0.119 ; 0.0) \\
(0.282 ; 0.319) \\
(0.209)\end{array}$ & $\begin{array}{c}(0.122 ; 0.0) \\
(0.285 ; 0.292) \\
(0.200)\end{array}$ & $\begin{array}{c}(0.123 ; 0.0) \\
(0.287 ; 0.269) \\
(0.192)\end{array}$ \\
\hline 0.2 & $\begin{array}{c}f_{i} \\
\pi_{i} \\
\Pi_{S B}\end{array}$ & - & $\begin{array}{c}(0.072 ; 0.0) \\
(0.220 ; 0.478) \\
(0.256)\end{array}$ & $\begin{array}{c}(0.087 ; 0.0) \\
(0.241 ; 0.445) \\
(0.235)\end{array}$ & $\begin{array}{c}(0.101 ; 0.0) \\
(0.259 ; 0.406) \\
(0.217)\end{array}$ & $\begin{array}{c}(0.111 ; 0.0) \\
(0.272 ; 0.366) \\
(0.202)\end{array}$ & $\begin{array}{c}(0.118 ; 0.0) \\
(0.280 ; 0.329) \\
(0.190)\end{array}$ & $\begin{array}{c}(0.121 ; 0.0) \\
(0.285 ; 0.298) \\
(0.180)\end{array}$ & $\begin{array}{c}(0.123 ; 0.0) \\
(0.287 ; 0.272) \\
(0.172)\end{array}$ \\
\hline 0.3 & $\begin{array}{c}f_{i} \\
\pi_{i} \\
\Pi_{S B} \\
\end{array}$ & - & - & $\begin{array}{c}(0.074 ; 0.0) \\
(0.223 ; 0.473) \\
(0.221)\end{array}$ & $\begin{array}{c}(0.091 ; 0.0) \\
(0.246 ; 0.434) \\
(0.200)\end{array}$ & $\begin{array}{c}(0.106 ; 0.0) \\
(0.265 ; 0.388) \\
(0.184)\end{array}$ & $\begin{array}{c}(0.115 ; 0.0) \\
(0.277 ; 0.344) \\
(0.170)\end{array}$ & $\begin{array}{c}(0.121 ; 0.0) \\
(0.284 ; 0.307) \\
(0.160)\end{array}$ & $\begin{array}{c}(0.123 ; 0.0) \\
(0.286 ; 0.276) \\
(0.151)\end{array}$ \\
\hline 0.4 & $\begin{array}{c}f_{i} \\
\pi_{i} \\
\Pi_{S B} \\
\end{array}$ & - & - & - & $\begin{array}{c}(0.077 ; 0.0) \\
(0.227 ; 0.468) \\
(0.186)\end{array}$ & $\begin{array}{c}(0.096 ; 0.0) \\
(0.253 ; 0.419) \\
(0.167)\end{array}$ & $\begin{array}{c}(0.111 ; 0.0) \\
(0.272 ; 0.366) \\
(0.151)\end{array}$ & $\begin{array}{c}(0.119 ; 0.0) \\
(0.282 ; 0.319) \\
(0.140)\end{array}$ & $\begin{array}{c}(0.123 ; 0.0) \\
(0.286 ; 0.280) \\
(0.131)\end{array}$ \\
\hline 0.5 & $\begin{array}{c}f_{i} \\
\pi_{i} \\
\Pi_{S B} \\
\end{array}$ & - & - & - & - & $\begin{array}{c}(0.081 ; 0.0) \\
(0.232 ; 0.459) \\
(0.152)\end{array}$ & $\begin{array}{c}(0.103 ; 0.0) \\
(0.262 ; 0.398) \\
(0.133)\end{array}$ & $\begin{array}{c}(0.117 ; 0.0) \\
(0.279 ; 0.336) \\
(0.120)\end{array}$ & $\begin{array}{c}(0.122 ; 0.0) \\
(0.286 ; 0.287) \\
(0.110)\end{array}$ \\
\hline 0.6 & $\begin{array}{c}f_{i} \\
\pi_{i} \\
\Pi_{S B}\end{array}$ & - & - & - & - & - & $\begin{array}{c}(0.087 ; 0.0) \\
(0.241 ; 0.445) \\
(0.117)\end{array}$ & $\begin{array}{c}(0.111 ; 0.0) \\
(0.272 ; 0.366) \\
(0.101)\end{array}$ & $\begin{array}{c}(0.121 ; 0.0) \\
(0.285 ; 0.298) \\
(0.090)\end{array}$ \\
\hline 0.7 & $\begin{array}{c}f_{i} \\
\pi_{i} \\
\Pi_{S B}\end{array}$ & - & - & - & - & - & - & $\begin{array}{c}(0.096 ; 0.0) \\
(0.253 ; 0.419) \\
(0.083)\end{array}$ & $\begin{array}{c}(0.119 ; 0.0) \\
(0.282 ; 0.319) \\
(0.070)\end{array}$ \\
\hline 0.8 & $\begin{array}{c}f_{i} \\
\pi_{i} \\
\Pi_{S B}\end{array}$ & - & - & - & - & - & - & - & $\begin{array}{c}(0.111 ; 0.0) \\
(0.272 ; 0.366) \\
(0.050)\end{array}$ \\
\hline
\end{tabular}

Table 10: Optimal results case 1c: $k_{1}=1, k_{2}=1, \gamma_{1}=1, \gamma_{2}=1, r_{1}=1, r_{2}=1, \sigma_{1}=4, \sigma_{2}=1$ 


\begin{tabular}{|c|c|c|c|c|c|c|c|c|c|}
\hline$t_{1} \mid t_{2}$ & & 0.2 & 0.3 & 0.4 & 0.5 & 0.6 & 0.7 & 0.8 & 0.9 \\
\hline 0.1 & $\begin{array}{c}f_{i} \\
\pi_{i} \\
\Pi_{S B}\end{array}$ & $\begin{array}{c}(0.0 ;-4.87) \\
(0.567 ; 0.920) \\
(4.858)\end{array}$ & $\begin{array}{c}(0.0 ;-4.727) \\
(0.674 ; 0.907) \\
(4.293)\end{array}$ & $\begin{array}{c}(0.0 ;-4.404) \\
(0.852 ; 0.875) \\
(3.755)\end{array}$ & $\begin{array}{c}(0.0 ;-3.764) \\
(1.087 ; 0.809) \\
(3.273)\end{array}$ & $\begin{array}{c}(0.0 ;-2.987) \\
(1.280 ; 0.721) \\
(2.877)\end{array}$ & $\begin{array}{c}(0.0 ;-2.335) \\
(1.392 ; 0.637) \\
(2.566)\end{array}$ & $\begin{array}{c}(0.0 ;-1.850) \\
(1.448 ; 0.567) \\
(2.322)\end{array}$ & $\begin{array}{c}(0.0 ;-1.496) \\
(1.472 ; 0.510) \\
(2.127)\end{array}$ \\
\hline 0.2 & $\begin{array}{c}f_{i} \\
\pi_{i} \\
\Pi_{S B}\end{array}$ & - & $\begin{array}{c}(0.0 ;-4.853) \\
(0.577 ; 0.919) \\
(4.254)\end{array}$ & $\begin{array}{c}(0.0 ;-4.671) \\
(0.711 ; 0.901) \\
(3.694)\end{array}$ & $\begin{array}{c}(0.0 ;-4.201) \\
(0.938 ; 0.855) \\
(3.169)\end{array}$ & $\begin{array}{c}(0.0 ;-3.370) \\
(1.194 ; 0.766) \\
(2.723)\end{array}$ & $\begin{array}{c}(0.0 ;-2.559) \\
(1.358 ; 0.667) \\
(2.377)\end{array}$ & $\begin{array}{c}(0.0 ;-1.957) \\
(1.438 ; 0.583) \\
(2.114)\end{array}$ & $\begin{array}{c}(0.0 ;-1.534) \\
(1.471 ; 0.517) \\
(1.910)\end{array}$ \\
\hline 0.3 & $\begin{array}{c}f_{i} \\
\pi_{i} \\
\Pi_{S B} \\
\end{array}$ & - & - & $\begin{array}{c}(0.0 ;-4.836) \\
(0.592 ; 0.917) \\
(3.652)\end{array}$ & $\begin{array}{c}(0.0 ;-4.577) \\
(0.766 ; 0.892) \\
(3.097)\end{array}$ & $\begin{array}{c}(0.0 ;-3.872) \\
(1.054 ; 0.821) \\
(2.595)\end{array}$ & $\begin{array}{c}(0.0 ;-2.883) \\
(1.300 ; 0.708) \\
(2.199)\end{array}$ & $\begin{array}{c}(0.0 ;-2.108) \\
(1.421 ; 0.606) \\
(1.909)\end{array}$ & $\begin{array}{c}(0.0 ;-1.586) \\
(1.468 ; 0.525) \\
(1.694)\end{array}$ \\
\hline 0.4 & $\begin{array}{c}f_{i} \\
\pi_{i} \\
\Pi_{S B}\end{array}$ & - & - & - & $\begin{array}{c}(0.0 ;-4.810) \\
(0.614 ; 0.915) \\
(3.049)\end{array}$ & $\begin{array}{c}(0.0 ;-4.404) \\
(0.852 ; 0.875) \\
(2.503)\end{array}$ & $\begin{array}{c}(0.0 ;-3.370) \\
(1.194 ; 0.766) \\
(2.042)\end{array}$ & $\begin{array}{c}(0.0 ;-2.335) \\
(1.392 ; 0.637) \\
(1.711)\end{array}$ & $\begin{array}{c}(0.0 ;-1.659) \\
(1.463 ; 0.537) \\
(1.480)\end{array}$ \\
\hline 0.5 & $\begin{array}{c}f_{i} \\
\pi_{i} \\
\Pi_{S B} \\
\end{array}$ & - & - & - & - & $\begin{array}{c}(0.0 ;-4.765) \\
(0.648 ; 0.910) \\
(2.447)\end{array}$ & $\begin{array}{c}(0.0 ;-4.056) \\
(0.992 ; 0.840) \\
(1.920)\end{array}$ & $\begin{array}{c}(0.0 ;-2.705) \\
(1.333 ; 0.686) \\
(1.524)\end{array}$ & $\begin{array}{c}(0.0 ;-1.770) \\
(1.455 ; 0.555) \\
(1.266)\end{array}$ \\
\hline 0.6 & $\begin{array}{c}f_{i} \\
\pi_{i} \\
\Pi_{S B}\end{array}$ & - & - & - & - & - & $\begin{array}{c}(0.0 ;-4.671) \\
(0.711 ; 0.901) \\
(1.847)\end{array}$ & $\begin{array}{c}(0.0 ;-3.370) \\
(1.194 ; 0.766) \\
(1.361)\end{array}$ & $\begin{array}{c}(0.0 ;-1.957) \\
(1.438 ; 0.583) \\
(1.057)\end{array}$ \\
\hline 0.7 & $\begin{array}{c}f_{i} \\
\pi_{i} \\
\Pi_{S B}\end{array}$ & - & - & - & - & - & - & $\begin{array}{c}(0.0 ;-4.404) \\
(0.852 ; 0.875) \\
(1.252)\end{array}$ & $\begin{array}{c}(0.0 ;-2.334) \\
(1.392 ; 0.637) \\
(0.855)\end{array}$ \\
\hline 0.8 & $\begin{array}{c}f_{i} \\
\pi_{i} \\
\Pi_{S B}\end{array}$ & - & - & - & - & - & - & - & $\begin{array}{c}(0.0 ;-3.370) \\
(1.194 ; 0.766) \\
(0.681)\end{array}$ \\
\hline
\end{tabular}

Table 11: Optimal results case 2a: $k_{1}=1, k_{2}=5, \gamma_{1}=1, \gamma_{2}=2, r_{1}=1, r_{2}=1, \sigma_{1}=1, \sigma_{2}=1$ 


\begin{tabular}{|c|c|c|c|c|c|c|c|c|c|}
\hline$t_{1} \mid t_{2}$ & & 0.2 & 0.3 & 0.4 & 0.5 & 0.6 & 0.7 & 0.8 & 0.9 \\
\hline 0.1 & $\begin{array}{c}f_{i} \\
\pi_{i} \\
\Pi_{S B} \\
\end{array}$ & $\begin{array}{c}(0.0 ;-2.400) \\
(0.566 ; 0.752) \\
(4.016) \\
\end{array}$ & $\begin{array}{c}(0.0 ;-2.321) \\
(0.670 ; 0.739) \\
(3.557) \\
\end{array}$ & $\begin{array}{c}(0.0 ;-2.144) \\
(0.833 ; 0.710) \\
(3.121)\end{array}$ & $\begin{array}{c}(0.0 ;-1.822) \\
(1.036 ; 0.655) \\
(2.735) \\
\end{array}$ & $\begin{array}{c}(0.0 ;-1.451) \\
(1.198 ; 0.584) \\
(2.417) \\
\end{array}$ & $\begin{array}{c}(0.0 ;-1.141) \\
(1.292 ; 0.518) \\
(2.167)\end{array}$ & $\begin{array}{c}(0.0 ;-0.909) \\
(1.340 ; 0.462) \\
(1.969)\end{array}$ & $\begin{array}{c}(0.0 ;-0.738) \\
(1.361 ; 0.417) \\
(1.810) \\
\end{array}$ \\
\hline 0.2 & $\begin{array}{c}f_{i} \\
\pi_{i} \\
\Pi_{S B}\end{array}$ & - & $\begin{array}{c}(0.0 ;-2.394) \\
(0.576 ; 0.750) \\
(3.518)\end{array}$ & $\begin{array}{c}(0.0 ;-2.288) \\
(0.704 ; 0.734) \\
(3.062)\end{array}$ & $\begin{array}{c}(0.0 ;-2.038) \\
(0.909 ; 0.692) \\
(2.639)\end{array}$ & $\begin{array}{c}(0.0 ;-1.633) \\
(1.126 ; 0.620) \\
(2.281)\end{array}$ & $\begin{array}{c}(0.0 ;-1.247) \\
(1.263 ; 0.542) \\
(2.003)\end{array}$ & $\begin{array}{c}(0.0 ;-0.960) \\
(1.331 ; 0.475) \\
(1.791)\end{array}$ & $\begin{array}{c}(0.0 ;-0.756) \\
(1.359 ; 0.422) \\
(1.625)\end{array}$ \\
\hline 0.3 & $\begin{array}{c}f_{i} \\
\pi_{i} \\
\Pi_{S B} \\
\end{array}$ & - & - & $\begin{array}{c}(0.0 ;-2.384) \\
(0.590 ; 0.749) \\
(3.020)\end{array}$ & $\begin{array}{c}(0.0 ;-2.236) \\
(0.755 ; 0.725) \\
(2.570)\end{array}$ & $\begin{array}{c}(0.0 ;-1.875) \\
(1.008 ; 0.664) \\
(2.167)\end{array}$ & $\begin{array}{c}(0.0 ;-1.401) \\
(1.215 ; 0.574) \\
(1.849)\end{array}$ & $\begin{array}{c}(0.0 ;-1.032) \\
(1.317 ; 0.493) \\
(1.615)\end{array}$ & $\begin{array}{c}(0.0 ;-0.781) \\
(1.357 ; 0.429) \\
(1.441)\end{array}$ \\
\hline 0.4 & $\begin{array}{c}f_{i} \\
\pi_{i} \\
\Pi_{S B} \\
\end{array}$ & - & - & - & $\begin{array}{c}(0.0 ;-2.368) \\
(0.611 ; 0.747) \\
(2.523) \\
\end{array}$ & $\begin{array}{c}(0.0 ;-2.144) \\
(0.833 ; 0.710) \\
(2.081)\end{array}$ & $\begin{array}{c}(0.0 ;-1.633) \\
(1.126 ; 0.620) \\
(1.711)\end{array}$ & $\begin{array}{c}(0.0 ;-1.141) \\
(1.292 ; 0.518) \\
(1.445)\end{array}$ & $\begin{array}{c}(0.0 ;-0.817) \\
(1.353 ; 0.438) \\
(1.257)\end{array}$ \\
\hline 0.5 & $\begin{array}{c}f_{i} \\
\pi_{i} \\
\Pi_{S B} \\
\end{array}$ & - & - & - & - & $\begin{array}{c}(0.0 ;-2.342) \\
(0.645 ; 0.742) \\
(2.026)\end{array}$ & $\begin{array}{c}(0.0 ;-1.965) \\
(0.955 ; 0.680) \\
(1.601)\end{array}$ & $\begin{array}{c}(0.0 ;-1.317) \\
(1.243 ; 0.557) \\
(1.283)\end{array}$ & $\begin{array}{c}(0.0 ;-0.870) \\
(1.346 ; 0.452) \\
(1.075)\end{array}$ \\
\hline 0.6 & $\begin{array}{c}f_{i} \\
\pi_{i} \\
\Pi_{S B}\end{array}$ & - & - & - & - & - & $\begin{array}{c}(0.0 ;-2.288) \\
(0.704 ; 0.734) \\
(1.531)\end{array}$ & $\begin{array}{c}(0.0 ;-1.633) \\
(1.126 ; 0.620) \\
(1.140)\end{array}$ & $\begin{array}{c}(0.0 ;-0.960) \\
(1.331 ; 0.475) \\
(0.895)\end{array}$ \\
\hline 0.7 & $\begin{array}{c}f_{i} \\
\pi_{i} \\
\Pi_{S B}\end{array}$ & - & - & - & - & - & - & $\begin{array}{c}(0.0 ;-2.144) \\
(0.833 ; 0.710) \\
(1.040)\end{array}$ & $\begin{array}{c}(0.0 ;-1.141) \\
(1.292 ; 0.518) \\
(0.722)\end{array}$ \\
\hline 0.8 & $\begin{array}{c}f_{i} \\
\pi_{i} \\
\Pi_{S B}\end{array}$ & - & - & - & - & - & - & - & $\begin{array}{c}(0.0 ;-1.633) \\
(1.126 ; 0.620) \\
(0.570)\end{array}$ \\
\hline
\end{tabular}

Table 12: Optimal results case $2 \mathrm{~b}: k_{1}=1, k_{2}=5, \gamma_{1}=1, \gamma_{2}=2, r_{1}=1, r_{2}=1, \sigma_{1}=1, \sigma_{2}=4$ 


\begin{tabular}{|c|c|c|c|c|c|c|c|c|c|}
\hline$t_{1} \mid t_{2}$ & & 0.2 & 0.3 & 0.4 & 0.5 & 0.6 & 0.7 & 0.8 & 0.9 \\
\hline 0.1 & $\begin{array}{c}f_{i} \\
\pi_{i} \\
\Pi_{S B} \\
\end{array}$ & $\begin{array}{c}(0.0778 ;-4.903) \\
(0.228 ; 0.923) \\
(4.721)\end{array}$ & $\begin{array}{c}(0.114 ;-4.840) \\
(0.275 ; 0.918) \\
(4.149)\end{array}$ & $\begin{array}{c}(0.204 ;-4.661) \\
(0.369 ; 0.900) \\
(3.589) \\
\end{array}$ & $\begin{array}{c}(0.487 ;-4.113) \\
(0.0539 ; 0.846) \\
(3.069) \\
\end{array}$ & $\begin{array}{c}(0.750 ;-3.222) \\
(0.707 ; 0.749) \\
(2.638)\end{array}$ & $\begin{array}{c}(0.961 ;-2.456) \\
(0.800 ; 0.654) \\
(2.307)\end{array}$ & $\begin{array}{c}(1.070 ;-1.906) \\
(0.845 ; 0.576) \\
(2.052)\end{array}$ & $\begin{array}{c}(1.117 ;-1.516) \\
(0.863 ; 0.513) \\
(1.853)\end{array}$ \\
\hline 0.2 & $\begin{array}{c}f_{i} \\
\pi_{i} \\
\Pi_{S B} \\
\end{array}$ & - & $\begin{array}{c}(0.081 ;-4.898) \\
(0.232 ; 0.923) \\
(4.133) \\
\end{array}$ & $\begin{array}{c}(0.129 ;-4.813) \\
(0.293 ; 0.915) \\
(3.562)\end{array}$ & $\begin{array}{c}(0.270 ;-4.516) \\
(0.424 ; 0.886) \\
(3.010) \\
\end{array}$ & $\begin{array}{c}(0.599 ;-3.675) \\
(0.632 ; 0.799) \\
(2.524) \\
\end{array}$ & $\begin{array}{c}(0.896 ;-2.717) \\
(0.773 ; 0.687) \\
(2.151) \\
\end{array}$ & $\begin{array}{c}(1.050 ;-2.026) \\
(0.837 ; 0.594) \\
(1.876) \\
\end{array}$ & $\begin{array}{c}(1.113 ;-1.558) \\
(0.861 ; 0.520) \\
(1.667)\end{array}$ \\
\hline 0.3 & $\begin{array}{c}f_{i} \\
\pi_{i} \\
\Pi_{S B} \\
\end{array}$ & - & - & $\begin{array}{c}(0.085 ;-4.890) \\
(0.239 ; 0.922) \\
(3.544)\end{array}$ & $\begin{array}{c}(0.154 ;-4.764) \\
(0.320 ; 0.910) \\
(2.976)\end{array}$ & $\begin{array}{c}(0.393 ;-4.223) \\
(0.512 ; 0.857) \\
(2.441)\end{array}$ & $\begin{array}{c}(0.787 ;-3.099) \\
(0.725 ; 0.734) \\
(2.010)\end{array}$ & $\begin{array}{c}(1.018 ;-2.197) \\
(0.824 ; 0.618) \\
(1.703)\end{array}$ & $\begin{array}{c}(1.108 ;-1.614) \\
(0.859 ; 0.530) \\
(1.482)\end{array}$ \\
\hline 0.4 & $\begin{array}{c}f_{i} \\
\pi_{i} \\
\Pi_{S B} \\
\end{array}$ & - & - & - & $\begin{array}{c}(0.092 ;-4.879) \\
(0.248 ; 0.921) \\
(2.956) \\
\end{array}$ & $\begin{array}{c}(0.204 ;-4.661) \\
(0.369 ; 0.900) \\
(2.393) \\
\end{array}$ & $\begin{array}{c}(0.599 ;-3.675) \\
(0.632 ; 0.799) \\
(1.893) \\
\end{array}$ & $\begin{array}{c}(0.961 ;-2.456) \\
(0.800 ; 0.654) \\
(1.538) \\
\end{array}$ & $\begin{array}{c}(1.099 ;-1.695) \\
(0.856 ; 0.543) \\
(1.298)\end{array}$ \\
\hline 0.5 & $\begin{array}{c}f_{i} \\
\pi_{i} \\
\Pi_{S B} \\
\end{array}$ & - & - & - & - & $\begin{array}{c}(0.104 ;-4.858) \\
(0.263 ; 0.919) \\
(2.368)\end{array}$ & $\begin{array}{c}(0.322 ;-4.395) \\
(0.463 ; 0.874) \\
(1.816)\end{array}$ & $\begin{array}{c}(0.849 ;-2.889) \\
(0.752 ; 0.709) \\
(1.386)\end{array}$ & $\begin{array}{c}(1.083 ;-1.817) \\
(0.850 ; 0.562) \\
(1.116)\end{array}$ \\
\hline 0.6 & $\begin{array}{c}f_{i} \\
\pi_{i} \\
\Pi_{S B} \\
\end{array}$ & - & - & - & - & - & $\begin{array}{c}(0.129 ;-4.813) \\
(0.293 ; 0.915) \\
(1.781) \\
\end{array}$ & $\begin{array}{c}(0.599 ;-3.675) \\
(0.632 ; 0.799) \\
(1.262) \\
\end{array}$ & $\begin{array}{c}(1.050 ;-2.026) \\
(0.837 ; 0.594) \\
(0.938) \\
\end{array}$ \\
\hline 0.7 & $\begin{array}{c}f_{i} \\
\pi_{i} \\
\Pi_{S B} \\
\end{array}$ & - & - & - & - & - & - & $\begin{array}{c}(0.204 ;-4.661) \\
(0.369 ; 0.900) \\
(1.196) \\
\end{array}$ & $\begin{array}{c}(0.961 ;-2.456) \\
(0.800 ; 0.654) \\
(0.769) \\
\end{array}$ \\
\hline 0.8 & $\begin{array}{c}f_{i} \\
\pi_{i} \\
\Pi_{S B}\end{array}$ & - & - & - & - & - & - & - & $\begin{array}{c}(0.599 ;-3.675) \\
(0.632 ; 0.799) \\
(0.631)\end{array}$ \\
\hline
\end{tabular}

Table 13: Optimal results case 2c: $k_{1}=1, k_{2}=5, \gamma_{1}=1, \gamma_{2}=2, r_{1}=1, r_{2}=1, \sigma_{1}=4, \sigma_{2}=1$ 


\section{References}

Anand, B./Sansing, R. (2000): The Weighting Game: Formula Apportionment as an Instrument of Public Policy, in: National Tax Journal 53, 183-199.

Bertrand, M./Mullainathan, S. (2000): Agents With and Without Principals, in: American Economic Review 90, 203-208.

Bertrand, M./Mullainathan, S. (2001): Are CEOs Rewarded for Luck? The Ones Without Principals Are, in: Quarterly Journal of Economics 66, 901-932.

Bettendorf, L./Devereux, M./van der Horst, A./Loretz, S./de Mooij, R. (2010): Corporate tax harmonization in the EU, in: Economic Policy 63, 537-590.

Bettendorf, L./Devereux, M./van der Horst, A./Loretz, S. (2011): Corporate Tax Reform in the EU: Weighing Pros and Cons, in: Oxford University Centre for Business Taxation, Policy Briefing, March 21, 2011.

Büttner, T./Riedel, N./Runkel, M. (2011): Strategic consolidation under formula apportionment, in: National Tax Journal 64, 225-254.

Devereux, M./Loretz, S. (2008): The Effects of EU Formula Apportionment on Corporate Tax Revenues, in: Fiscal Studies 29, 1-33.

Edmiston, K. (2002): Strategic Apportionment of the State Corporate Income Tax -An Applied General Equilibrium Analysis, in: National Tax Journal 55, 239-262. 
Edmiston, K./Arze del Granado, F. (2006): Economic Effects of Apportionment Formula Changes -Results from a Panel of Corporate Income Tax Returns, in: Public Finance Review 34, 483-504.

Eichner, T./Runkel, M. (2008): Why the European Union should adopt formula apportionment with a sales factor, in: Scandinavian Journal of Economics 110, 567-589.

Ernst $\mathcal{E}$ Young (2011): European Commission and the CCCTB, http:/ /tmagazine.ey.com/insights/european-commission-and-the-ccctb/

European Commission (2011): Proposal for a COUNCIL DIRECTIVE on a Common Consolidated Corporate Tax Base (CCCTB), COM(2011)121.

European Parliament (2012): European Parliament legislative resolution of 19 April 2012 on the proposal for a Council directive on a Common Consolidated Corporate Tax Base (CCCTB), P7-TA(2012)0135.

Federation of Tax Administrators (2013): State Apportionment of Corporate Income, www. taxadmin.org/fta/rate/apport.pdf

Fox, W./Murray, M./Luna, L. (2005): How Should a Subnational Corporate Income Tax on Multistate Businesses Be Structured?, in: National Tax Journal 58, 139-159.

Fuest, C./Hemmelgarn, T./Ramb, F. (2007) How would the introduction of an EU-wide formula apportionment affect the distribution and size of the corporate tax base? An analy-sis based on German multinationals, in: International Tax and Public Finance 
$14,605-626$.

Garst, M. (2008): An Overview of the Sales Apportionment Factor and its Application to Sales of Financial Instruments, in: Journal of State Taxation, 15-22 and 48-49.

Goolsbee, A./ Maydew, E. (2000): Coveting thy neighbor's manufacturing: the dilemma of state income apportionment, in: Journal of Public Economics 75, 125-143.

Gordon, R./Wilson, J. (1986): An Examination of Multijurisdictional Corporate Income Taxation under Formula Apportionment, in: Econometrica 54, 1357-1373.

Hellerstein, W./McLure, C. (2004): The European Commission's Report on Company Income Taxation: What the EU Can Learn from the Experience of the US States, in: International Tax and Public Finance 11, 199-220.

Institute on Taxation and Economic Policy (2012): Corporate Income Tax Apportionment and the "Single Sales Factor".

Klassen, K./Lang, M./Wolfson, M. (1993): Geographic Income Shifting by Multinational Corporations in Response to Tax Rate Changes, in: Journal of Accounting Research 31, 141-173.

Klassen, K./Shackelford, D. (1998): State and Provincial Corporate Tax Planning: Income Shifting and Sales Apportionment Factor Management, in: Journal of Accounting and Economics 25, 385-406. 
Lohman, J. (2012): Corporation Tax Income Apportionment Formulas, in: OLR Research Report, 2012-R-0414.

Martini, J./Niemann, R./Simons D. (2012): Transfer Pricing or Formula Apportionment? Tax-Induced Distortions of Multinationals" Investment and Production Decisions, in: Contemporary Accounting Research 29, 1060-1086.

McLure, C. E., Jr. 1981: The elusive incidence of the corporate income tax: The state case, in: Public Finance Quarterly 9, 395--413.

McLure, C./Weiner, J. (2000): Deciding Whether the European Union Should Adopt Formula Apportionment of Company Income, in: Cnossen, Sijbren (ed.): Taxing Capital Income in the European Union - Issues and Options for Reform, Oxford University Press, Oxford, New York, 243-292.

Mintz, J./Smart, M. (2004): Income Shifting, Investment, and Tax Competition: Theory and Evidence From Provincial Taxation in Canada, in: Journal of Public Economics $88,1149-1168$.

Mintz, J./Weiner, J. (2003): Exploring Formula Allocation for the European Union, in: International Tax and Public Finance 10, 695-711.

Musgrave, P. (1973): International Tax Base Division and the Multinational Corporation, in: Public Finance 27, 394-413.

Navaretti, G./Checchi, D./Turrini, A. (2003): Adjusting labor demand: Multinational ver- 
sus national firms: A cross-European analysis, Journal of the European Economic Association 1, 708-719

Nielsen, S./Raimondos-Møller, P./Schjelderup, G. (2008): Taxes and Decision Rights in Multinationals, in: Journal of Public Economic Theory 10, 245-258.

Niemann, R. (2008): The Impact of Differential Taxation on Managerial Effort and Risk Taking, in: FinanzArchiv Public Finance Analysis 64, 273-310.

Pethig, R./Wagener, A. (2007): Profit Tax Competition and Formula Apportionment, in: International Tax and Public Finance 14, 631-655.

Riedel, N. (2010): The downside of formula apportionment: evidence on factor demand distortions, in: International Tax and Public Finance 17, 236-258.

Riedel, N. (2011): Taxing multi-nationals under union wage bargaining, in: International Tax and Public Finance 18, 399-421.

Runkel, M./Schjelderup, G. (2011): The choice od formula apportionment factors under formula apportionment, in: International Economic Review 52, 913-934.

Shackelford, D./Slemrod, J. (1998): The Revenue Consequences of Using Formula Apportionment to Calculate U.S. and Foreign-Source Income: A Firm-Level Analysis, in: International Tax and Public Finance 5, 41-59.

Spremann, K. (1987): Agent and Principal, in: Bamberg, G., Spremann, K. (Hrsg.), Agency Theory, Information, and Incentives, Berlin, Springer, 3-38. 
Wellisch, D. (2004): Taxation under Formula Apportionment - Tax Competition, Tax Incidence, and the Choice of Apportionment Factors, in: FinanzArchiv 60, 24-41. 